\title{
Techniques and Protocols for Dispersing Nanoparticle Powders in Aqueous Media-is there a Rationale for Harmonization?
}

Hartmann, Nanna B.; Jensen, Keld Alstrup; Baun, Anders; Rasmussen, Kirsten; Rauscher, Hubert; Tantra, Ratna; Cupi, Denisa; Gilliland, Douglas; Pianella, Francesca; Riego Sintes, Juan M.

Published in:

Journal of Toxicology and Environmental Health. Part B: Critical Reviews

Link to article, DOI:

10.1080/10937404.2015.1074969

Publication date:

2015

Document Version

Peer reviewed version

Link back to DTU Orbit

Citation (APA):

Hartmann, N. B., Jensen, K. A., Baun, A., Rasmussen, K., Rauscher, H., Tantra, R., Cupi, D., Gilliland, D., Pianella, F., \& Riego Sintes, J. M. (2015). Techniques and Protocols for Dispersing Nanoparticle Powders in Aqueous Media-is there a Rationale for Harmonization? Journal of Toxicology and Environmental Health. Part B: Critical Reviews, 18(6), 299-326. https://doi.org/10.1080/10937404.2015.1074969

\section{General rights}

Copyright and moral rights for the publications made accessible in the public portal are retained by the authors and/or other copyright owners and it is a condition of accessing publications that users recognise and abide by the legal requirements associated with these rights.

- Users may download and print one copy of any publication from the public portal for the purpose of private study or research.

- You may not further distribute the material or use it for any profit-making activity or commercial gain

- You may freely distribute the URL identifying the publication in the public portal 


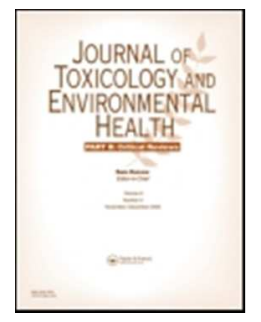

\section{Techniques and protocols for dispersing nanoparticle powders in aqueous media - is there a rational for harmonization?}

\begin{tabular}{|c|c|}
\hline Journal: & Journal of Toxicology and Environmental Health, Part B: Critical Reviews \\
\hline Manuscript ID: & UTEB-2015-0009.R1 \\
\hline Manuscript Type: & Review \\
\hline Date Submitted by the Author: & $\mathrm{n} / \mathrm{a}$ \\
\hline Complete List of Authors: & $\begin{array}{l}\text { Hartmann, Nanna; Technical University of Denmark, Department of } \\
\text { Environmental Engineering } \\
\text { Jensen, Keld; The National Research Centre for the Working Environment, } \\
\text { Baun, Anders; Technical University of Denmark, Department of } \\
\text { Environmental Engineering } \\
\text { Rasmussen, Kirsten; European Commission - Joint Research Centre, } \\
\text { Instutute for Health and Consumer Protection } \\
\text { Rauscher, Hubert; European Commission - Joint Research Centre, } \\
\text { Instutute for Health and Consumer Protection } \\
\text { Tantra, Ratna; National Physical Laboratory, } \\
\text { Cupi, Denisa; Technical University of Denmark, Department of } \\
\text { Environmental Engineering } \\
\text { Gilliland, Douglas; European Commission - Joint Research Centre, } \\
\text { Instutute for Health and Consumer Protection } \\
\text { Pianella, Francesca; European Commission - Joint Research Centre, } \\
\text { Instutute for Health and Consumer Protection } \\
\text { Riego Sintes, Juan; European Commission - Joint Research Centre, } \\
\text { Instutute for Health and Consumer Protection }\end{array}$ \\
\hline Keywords: & nanomaterials, harmonization, dispersion, OECD, test protocols \\
\hline
\end{tabular}

\section{SCHOLARONE ${ }^{m}$ \\ Manuscripts}


Techniques and protocols for dispersing nanoparticle powders in aqueous media - is there a rational for harmonization?

Nanna B. Hartmann ${ }^{1,2 *}$, Keld Alstrup Jensen ${ }^{3}$, Anders Baun ${ }^{1}$, Kirsten Rasmussen ${ }^{2}$, Hubert Rauscher $^{2}$, Ratna Tantra ${ }^{4}$, Denisa Cupi ${ }^{1}$, Douglas Gilliland ${ }^{2}$, Francesca Pianella ${ }^{2}$, Juan M. Riego Sintes $^{2}$

${ }^{1}$ Technical University of Denmark (DTU), Department of Environmental Engineering, Miljoevej, DK-2800 Kgs. Lyngby, Denmark.

${ }^{2}$ European Commission - Joint Research Centre, Via E. Fermi, 21027 Ispra, Italy

${ }^{3}$ The National Research Centre for the Working Environment (NRCWE), Lers $\varnothing$ Park Allé 105, DK2100 Copenhagen Oe, Denmark

${ }^{4}$ National Physical Laboratory (NPL), Hampton Road, Teddington, Middlesex TW11 0LW, United Kingdom

\author{
*Corresponding author. Current affiliation: DTU Environnement, Miljøvej, DK-2800 Kgs. Lyngby, \\ Denmark. Email: nibh@env.dtu.dk
}




\section{$1 \quad$ ABSTRACT}

2 Appropriate ways of bringing engineered nanoparticles (ENP) into aqueous dispersion is a main 3 obstacle for testing and thus for understanding and evaluating their potential adverse effects to the 4 environment and human health. Using different methods to prepare (stock) dispersions of same

5 ENP may be a source of variation in the toxicity measured. Harmonization and standardization of 6 dispersion methods applied in mammalian and ecotoxicity testing are needed to ensure a 7 comparable data quality and to minimize test artefacts produced by modifications of ENP during the 8 dispersion preparation process. Such harmonization and standardization will also enhance 9 comparability between tests, labs and studies on different types of ENP. The scope of this review 10 was to critically discuss the essential parameters in dispersion protocols for ENP. The parameters 11 are identified from individual scientific studies and from consensus reached in larger-scale research 12 projects and international organizations. A step-wise approach is proposed to develop tailored 13 dispersion protocols for ecotoxicological and mammalian toxicological testing of ENP. The 14 recommendations of this analysis may serve as a guide to researchers, companies, and regulators 15 when selecting, developing and evaluating the appropriateness of dispersion methods applied in 16 mammalian and ecotoxicity testing. However, additional experimentation is needed to further 17 document the protocol parameters and investigate to what extent different stock dispersion methods 18 affect ecotoxicological and mammalian toxicological responses of ENP. 


\section{INTRODUCTION}

The amount of information in literature on health and environmental safety of engineered nanoparticles (ENP) is steadily increasing. However, guidance is lacking on appropriate ways of performing tests with ENP in biological test systems (referring to toxicological or ecotoxicological tests using whole organisms or cells to determine potential adverse effects, here both are described as (eco)toxicity) and subsequently interpreting the results. This remains a barrier for understanding and evaluating potential adverse effects of ENP to humans and the environment. The lack of guidance is related to a limited understanding of the dynamic and complex behavior of ENP in different testing matrices making it difficult to provide appropriate scientific advice on the best testing practices (Cupi et al., 2015; Magdolenova et al, 2012; Snyder-Talkington et al, 2012).

Tests for ecotoxicity and mammalian toxicity generally require the preparation of particle dispersions where solid particles are dispersed in liquid media. Dispersions of ENP have also gained high interest for dosing in animal screening studies and for providing better control of the delivered dose as well as a faster and less expensive test procedure (Roursgaard et al., 2010). Testing dispersions of different concentrations are typically prepared by adding aliquots of a stock dispersion into a test medium. Unless the test substance is provided by the producer/supplier in the form of a stable stock dispersion, a stock dispersion will have to be prepared by dispersing the dry powder into a suitable dispersion medium. It has previously been shown that different suspension preparation methods can influence toxicity outcomes in ecotoxicity tests (Handy et al., 2008; Jo et al., 2012) and human toxicity tests where dispersion status plays a critical role for example in the fibrogenicity of single-walled carbon nanotubes (SWCNT) in human lung fibroblasts (Wang et al 2010b). It should be mentioned that, even if dispersion status is successfully controlled, other factors, such as administration route and adsorption affinity of the ENP to biomolecules and cell surfaces, is likely to cause variations in toxicity test outcomes. For example, differences in 
44 toxicokinetics were observed between dietary and intravenous exposure of ZnO ENP in rats (Choi 45 et al., 2015) as well as between dietary and aqueous exposure in zebrafish (Skjolding et al., 2014). 46 Also, adsorption of ENP onto cells and biomolecules was found to be variable depending on ENP 47 type (Hartmann et al., 2014; Lee et al., 2015).

48

Many ENP powders are not easily dispersed in aqueous media and their tendency to form agglomerates is a complicating factor which must be tackled in the preparation of stable stock dispersions. Dispersibility may be improved by adjustment of $\mathrm{pH}$ and/or ionic strengths or addition of solvents or dispersants combined with a de-agglomeration energy using various procedures for ultrasonication, stirring, or shaking (OECD, 2012; Jensen et al., 2014; Cupi, 2015). Once nanoparticle (NP) dispersion has been prepared its stability depends, among other things, on parameters related to the type of dispersion achieved, such as electrostatic, steric, polymeric or electrosteric, and the suspended particle concentration (Jensen et al., 2014).

Farré et al. (2009) and Godymchuk et al. (2011) provided an overview of some of the advantages and limitations of different dispersion preparation methods including mechanical, ultrasonication and chemical processes such as stirring or addition of dispersants. Based upon the evidence it is apparent that the choice of dispersion preparation method is often a trade-off between dispersion stability and risk of influencing test outcomes by introduction of toxic additives or changes to particle characteristics inducing significant or unknown changes in reactivity, solubility, and toxicity (Handy et al. 2008b; 2012a). . These possible testing artefacts may in part be responsible for the diverse results for biological effects. A well-known example is the false-positive inflammatory effects of fullerenes in the brain of juvenile sea-bass (Oberdörster, 2004). Effects were since attributed to $\gamma$-butyrolactone, a highly toxic oxidation product of tetrahydrofurene (TFH) that was used as a dispersant in the preparation of fullerene dispersions (Henry et al. 2007). More 

recently Menard et al. (2011) reviewed the literature on in vivo ecotoxicity of titanium dioxide $\left(\mathrm{TiO}_{2}\right)$ ENP and observed large variations which could not be clearly attributed to differences in test species or particle characteristics. It may be speculated that dispersion preparation methods might also play a role in this observed scatter in ecotoxicological effects of $\mathrm{TiO}_{2}$ (Hartmann, 2011). Thus, appropriate ways of bringing ENPs into dispersion is a critical and intensely debated topic in the scientific literature, research projects and international organizations such as the Organization for Economic Co-operation and Development (OECD), National Institute of Standards and Technology (NIST) and International Organization for Standardization (ISO).

Identification and further development of appropriate dispersion protocols is important both from a scientific and a regulatory point of view. Stock dispersion methods should ideally increase both accuracy and precision when adverse effects of ENP are tested by 1) minimizing artefacts produced by undesirable modifications of the ENP, 2) facilitating a link between observed effects and the physico-chemical properties of pristine ENP and 3) producing sufficiently stable and homogenous stock dispersions that enable precise and representative sampling when diluted into test dispersions also referred to as working dispersions. Harmonization of dispersion protocols signifies consistency between dispersion procedures and serves to minimize variations between testing systems, labs and nanomaterials. Finally, adherence to a validated technical guidance document for dispersion protocols infers that quality and validity criteria can be established with regard to stock dispersion stability and state of dispersion.

Several protocols for preparation of dispersions of ENP for toxicity testing have already been proposed through research projects such as ENPRA (Jacobsen, 2010) PROSPEcT (PROSPEcT, 2010), NANOGENOTOX (Jensen et al, 2011a), and NANOMMUNE (Nanommune, 2011) as well as organizations and institutes for guidance and standardized methods, such as NIST and the Center for the Environmental Implications of NanoTechnology (CEINT) (Taurozzi et al 2012a; 2012b; 
92 2012c; 2012d; 2013). Current protocols, as listed above and in Table 1, represent a development 93 and refinement in dispersion methods over the last years as knowledge on ENP behavior and 94 transformations during the different steps of dispersion has emerged. Hence, increasing focus is 95 being placed on appropriate ways of dispersion ENP without altering the particle properties or 96 creating test artefacts. However, the current protocols are limited in scope by being focused on 97 specific test types such as in vitro testing and/or certain ENP, and may have been optimized 98 according to specific criteria including dispersion stability and/or particle size distribution. This 99 limitation in scope may in some cases limit the direct applicability of existing protocols to other test 100 systems and their applicability to other ENP types. At the same time different labs may have 101 different 'traditions' for using specific dispersion media and procedures, which are likely to be 102 adapted to the specific purpose of the study and availability of equipment combined with past 103 practice. Labs may wish to adhere to already applied procedures for the sake of internal 104 comparability. However, this may limit inter-lab comparisons.

105 From a regulatory point of view, harmonization and standardization of protocols and methods 106 applied in (eco)toxicity testing is needed to ensure repeatability and reproducibility as well as a 107 comparable high quality of data, resulting in data upon which classification, labelling, and hazard 108 assessments can be based. The OECD plays a key role in the international harmonization of 109 regulatory guidelines for testing of chemicals (OECD, 2013). The agreement on mutual acceptance 110 of data (MAD), aimed at reducing testing efforts (OECD, 1981), is based on such harmonization. 111 Within the OECD Working Party on Manufactured Nanomaterials (WPMN) work is ongoing on 112 issues related to testing of nanomaterials, with one output being a "Guidance on Sample Preparation 113 and Dosimetry for the Safety Testing of Manufactured Nanomaterials" (GSPD) (OECD, 2012).

114 This guidance has a generic nature and outlines considerations relevant to physicochemical 115 characterization and biological tests based on available scientific knowledge. The lack of specific 
116 guidance is explained by the fact that “...best methods for sample preparation, dosimetry, and 117 safety testing do not yet have full consensus within the field..."(OECD, 2012). An OECD WPMN 118 expert meeting on ecotoxicology and environmental fate was held in Berlin in January 2013 to 119 discuss the applicability and further development of OECD test guidelines and guidance documents 120 for nanomaterials. One recommendation from the meeting was to amend the OECD GSPD to 121 include more detailed information on stock dispersion preparation (Kühnel \& Nickel 2014). For all 122 guidance update and development, the current challenge is to integrate the state-of-the art scientific 123 knowledge on dispersion techniques with the regulatory requirements for a harmonized approach.

124 The initial stock dispersion preparation is identified as a fundamental step in obtaining 125 meaningful results in subsequent (eco)toxicity testing. Therefore, the present study aimed to 126 contribute to development of appropriate protocols for preparation of aqueous stock dispersions of 127 ENP powders. This was achieved through a critical review of 5 available dispersion protocols from 128 NANOGENOTOX, PROSPEcT, NANOMMUNE, ENPRA and NIST/CEINT. Basis upon our 129 observations key steps in the in dispersion procedures were identified. Combined with a review of 130 published scientific papers this provided background knowledge in a subsequent discussion on how 131 these parameters influence the resulting (eco)toxicity and dispersion characteristics. Special 132 emphasis was placed on sonication procedures and parameters as these were identified as a key step 133 in the dispersion preparation. This investigation was undertaken to identify research and 134 documentation needs and potential areas of harmonization for the preparation of stable aqueous 135 stock dispersions from powders of ENP. The provided information is intended to minimize the risk 136 that the preparation methods produce undesirable modifications of ENP by inducing testing 137 artefacts. The subsequent dilution and characterization in testing media is addressed when relevant, 138 but a detailed description hereof is outside the main scope of this review (for additional information 139 on this the reader is referred to Jensen et al. 2014; Seitz et al. 2013; Handy et al. 2012a; 2012b). 
140 With the proposal of a tailored dispersion protocol this investigation is intended as a starting point

141 for development of a guidance document on stock dispersion protocols for (eco)toxicological

142 testing assisting the production of reliable and reproducible (eco)toxicity data for MAD purposes

143 under the Globally Harmonized System of Classification and Labelling of Chemicals (GHS) (in

144 Europe this corresponds to the $\operatorname{REACH}(\mathrm{EC}, 2006)$ and CLP $(\mathrm{EC}, 2008)$ regulations, respectively).

145

146

147

148

149

150

151

152

153

154

155

156

157

158

159

160

161

162

163

\section{STOCK DISPERSION PREPARATION - REVIEW OF KEY PARAMETERS}

\section{Case study protocols: overview, commonalities and differences}

For the purpose of this review 5 specific dispersion protocols were selected as case studies. An overview of these is provided in Table 1. Although the protocols vary greatly in some parameter values, the parameters listed are comparable. Based on information in the protocols, the following parameters were identified as key considerations in a stock dispersion preparation protocol:

$$
\text { I) ENP properties }
$$

II) ENP stock concentrations

III) Volume of dispersion medium

IV) Dispersion media / water quality

V) Stabilizing / dispersing agents

VI) Pre-wetting of ENP powders

VII) Dispersion procedure (mechanical and ultrasonication)

VIII) Temperature control

IX) Maintaining stability prior to dosing

X) Performance or quality assurance

All of these parameters are described for the individual protocols in Table 1 below and frame the discussions and recommendations in the remaining part of this review. Additional critical 
164 parameters, not listed in Table 1, include the type of vials, immersion depth of the sonifier in probe 165 dispersion protocols and position of vials in the case of ultrasound bath sonicators. Moreover, the 166 importance of considering the sequence of dispersion preparation steps was pointed out by Byrne et 167 al. (2010).

\section{Considerations related to nanomaterial properties}

171 ENP to be dispersed. Basic information on the physicochemical properties needs to be obtained by 172 compiling existing data from the producers' technical data sheets and verifying and supplementing 173 this information by additional physicochemical characterization as relevant. The required 174 information includes information on particle composition, chemical surface properties, water 175 solubility and hydrophobicity. Finally, morphological characterization of the aggregate size (176 distribution) and types of agglomerates in the ENP powder is valuable for setting expectations for 177 hydrodynamic size-distributions in dispersion. The dispersibility of ENP depends on the 178 mechanisms underlying agglomeration in the ENP powder, which often occurs due to electrostatic 179 forces. Other agglomeration mechanisms include physical interlock, electric, magnetic, and soft 180 bridging (Schneider \& Jensen 2009; Jensen et al., 2014). ENP agglomerated due to specific 181 subcategories such as entanglement, bridging due to organic coatings and stickiness, and 182 ferromagnetic properties may be particularly difficult to disperse as compared to the typically 183 considered van der Waals forces. In such cases, acceptance of larger agglomerates in the dispersion 184 may be necessary as separation into single particles or primary aggregates may not be feasible and 185 agglomeration is inevitable.

186 The protocols reviewed in the present study have been documented mainly for metal oxides 187 (cerium oxide $\left(\mathrm{CeO}_{2}\right)$, zinc oxide $(\mathrm{ZnO}), \mathrm{TiO}_{2}$ and silicon dioxide $\left(\mathrm{SiO}_{2}\right)$ ) although three also apply 
188 (one with adaptations) to carbon nanotubes (CNT), one to silver (Ag) Ag ENP and one to iron (Fe)

189 ENP. On an operational level, ENP with similar surface characteristics may in principle be 190 dispersed using the same procedure. This means that if a dispersion method has already been

191 applied to one hydrophilic ENP it may also be appropriate to other hydrophilic ENP. What is 192 understood by 'similar' is largely a matter of interpretation, and is also related to the broader on193 going discussions on grouping of nanomaterials which is needed for testing, risk assessment and 194 'safety-by-design' purposes. In this regard, it is important to note that grouping based on chemical 195 composition like metal oxides, metals, and carbon-containing nanomaterials will not necessarily be 196 operational for identification of appropriate dispersion protocols. For example uncoated $\mathrm{ZnO}, \mathrm{SiO}_{2}$ 197 and $\mathrm{TiO}_{2}$ ENPs typically have iso-electric points around neutral, acidic and acidic/neutral $\mathrm{pH}$ levels, 198 respectively (Komulski, 2009), resulting in highly different dispersibility and stability in pure water 199 systems, when no additional steps are taken to stabilize the dispersion. These differences may be 200 more pronounced in pure water compared to biological media. A range of metal oxide ENP, with 201 varying zeta potential in deionized water ranging from $-29.2 \mathrm{mV}$ to $57.2 \mathrm{mV}$, displayed similar 202 very similar zeta potentials ranging from $-26.6 \mathrm{mV}$ to $-19.8 \mathrm{mV}$ in cell medium containing $5 \%$ fetal 203 bovine serum (Lee et al., 2015). Hence, depending on the stock dispersion media composition, 204 differences in zeta potential and stability between different ENP may even out. whereas toxicologists prepare test dispersions cell media or perform in vivo studies using lung 210 instillation, ingestion, and intravenous injection. These different exposure methods may require 211 different minimum concentrations in the stock dispersion. Conversely an upper limit for stock 
212 concentrations may be determined by concentrations at which extensive agglomeration occurs for 213 specific ENP and medium. In the evaluated dispersion protocols presented in Table 1 the stock 214 dispersion concentrations varied from 0.015 to $20 \mathrm{~g} / \mathrm{L}$. The NIST protocol prescribed concentrations 215 from $0.5-20 \mathrm{~g} / \mathrm{L}$ (Taurozzi et al, 2012c) with subsequent dilution to achieve test dispersions of 0.1 $216 \mathrm{~g} / \mathrm{L}$ in phosphate buffered saline solution (PBS) and Dulbecco's Modified Eagle Medium containing $21710 \%$ fetal bovine serum (DMEM-FBS) (Taurozzi et al, 2012d) or synthetic environmental medium 218 (Taurozzi et al, 2013). The NANOGENOTOX and ENPRA protocols prescribe a stock 219 concentration of $2.56 \mathrm{~g} / \mathrm{L}$, whereas the concentrations in the NANOMMUNE and PROSPEcT 220 protocols are particle-dependent and vary from $0.015 \mathrm{~g} / \mathrm{L}\left(\mathrm{CeO}_{2}\right.$, PROSPEcT) and $0.25 \mathrm{~g} / \mathrm{L}(\mathrm{CNT}$ 221 in the NANOMMUNE protocol) to $1 \mathrm{~g} / \mathrm{L}$ (general concentration in the NANOMMUNE protocol) 222 and $2.56 \mathrm{~g} / \mathrm{L}$ (for coated $\mathrm{ZnO}$, in the PROSPEcT protocol). The $2.56 \mathrm{~g} / \mathrm{L}$ in the ENPRA protocol, 223 and since adopted in the NANOGENOTOX and PROSPEcT protocols, were selected based on (1) 224 dose requirements from the toxicologists and (2) to obtain a simple dilution scheme for in vitro 225 toxicological dosing without diluting the test medium significantly while at the same time enabling 226 direct instilling or injection of sufficiently low volumes in test animals.

227 Increasing the material concentrations in dispersions enhances the likelihood of collision, 228 agglomeration and aggregation. Agglomerates are clusters of weakly bound particles, which may be 229 separated again, whereas aggregates consist of strongly bonded or fused primary particles (ISO, 230 2008). Hence, if aggregation (irreversible process) occurs in the stock dispersions no subsequent 231 steps in the dispersion preparation procedure are successful in separating the aggregates and this 232 ultimately results in testing of large particle aggregates rather than smaller (primary) particles.

233 Since the critical maximum concentration that induces agglomeration depends on the ENP 234 properties such as whether they are charged/uncharged, hydrophilic, hydrophobic, magnetic, 235 conductive, soluble/insoluble, initially aggregated or agglomerated and the type of stabilization 
236 such as electrostatic, steric or electrosteric, it is necessary to consider the critical concentrations for 237 agglomeration with respect to the specific ENP to be dispersed. In a generic dispersion protocol the 238 fixed ENP concentration may exceed the particle saturation level for some ENP, and therefore 239 represents a trade-off when using generic dispersion protocols with fixed conditions. To counteract 240 concentration-induced agglomeration one can either try to adjust the preparation techniques and 241 ratios between ENP and dispersants as illustrated by modifications of the NANOGENOTOX 242 dispersion protocol (Guiot and Spalla, 2012). The use of dispersants will be discussed further later. 243 The relationship between concentration and aggregation in stock dispersions was investigated 244 for $\mathrm{TiO}_{2}$ (NM-105) by Tantra et al. (2014). This study investigated the influence on the final $\mathrm{TiO}_{2}$ 245 dispersion properties as a result of systematic changes in different steps within one dispersion 246 protocol (e.g. dispersion ageing, sonication time (20 sec - $15 \mathrm{~min}$ ), sonication power (in W), pulsed 247 operation mode, amplitude, sonication in the presence/absence of an ice bath, material subsampling, 248 particle concentration). It was concluded that $\mathrm{TiO}_{2}$ particle concentration in the stock dispersion 249 was the most influencing factor for dispersion properties. Six concentrations were tested, ranging 250 from 0.015 to $2.6 \mathrm{~g} / 1$ and a concentration-dependent shift in particle size distributions was observed 251 with higher particle concentrations resulting in a greater degree of aggregation/agglomeration. 252 Studies by Hartmann et al. (2012) and Ji et al. (2010) found that dispersions of $\mathrm{TiO}_{2}(\mathrm{P} 25$ Evonik) 253 ENP in ultrapure water prepared by ultrasonication were stable for minimum of 6 and $24 \mathrm{hr}$ 254 respectively at particle concentrations of $2-100 \mathrm{mg} / \mathrm{L}$ as evaluated by visual inspections, UV-Vis, 255 DLS, and zeta potential. Previously Tantra et al (2010) noted a relationship between particle 256 concentration, zeta potential and stability of ENP systems for multi-walled carbon nanotubes 257 (MWCNT), gold and silica ENP. The samples used were commercially bought (highly stable) 258 colloidal suspensions; the dispersion medium of the gold nanoparticles was not specified by the 259 supplier (Tantra et al., 2010), whereas the other three were suspended in deionized water based 
260 media. The study reported that there is a distinctive region (referred to as the 'stable region') in the 261 plots of zeta-potential versus particle concentration, in which the zeta-potential value is independent 262 of nanoparticle concentration. Results from the study showed that all samples were highly stable, as 263 indicated by their large negative zeta-potential values, with average mean ranging from - 43 to - 56 $264 \mathrm{mV}$. The average standard deviation of measurement within the stable region was reported to be 265 within $+/-4 \mathrm{mV}$; it was only at extreme dilutions (referred to as the 'unstable region) that the mean 266 value of the zeta-potential changed. The 'stable region' for hydrodynamic diameter and zeta 267 potential with a lower limit for particle concentration between $10^{-4}$ and $10^{-2} \mathrm{wt} \%$ depending on 268 particle type (corresponding to approximately $0.1-10 \mathrm{~g} / \mathrm{L}$ ). Clearly, it was not the intent of such 269 studies to give specific recommendations on particle concentrations, as case-specific interplay 270 between concentrations, ionic strength, stabilizing agents, $\mathrm{pH}$, has to be taken into account. 271 However, such studies are indicative of how easy it is to vary dispersion quality as a result of small 272 changed made to the protocol e.g. particle concentration.

273 The resulting hydrodynamic size in the stock dispersions and in test media is not only relevant 274 for having control of the initial exposure characteristics, but also for potential mechanisms and 275 observed biological effects (Jensen et al., 2014). In ecotoxicological tests greater toxicity was 276 observed for Ag and Au ENP when they were less agglomerated in a diluted exposure medium for 277 D. magna (Römer et al., 2013) and zebra fish embryos (Truong et al., 2012). As lower ENP 278 concentrations and lower ionic strength of the media is likely to causes less agglomeration it is 279 therefore plausible that a higher relative toxicity may be observed at lower particle concentrations in 280 low ionic strength media (Baun et al., 2008; Römer et al., 2013; Cupi, 2015). The agglomeration 281 and aggregation state in the stock dispersion is therefore crucial for subsequent exposure and effects 282 in (eco) toxicological testing. Data suggest that sufficiently stable stock dispersions often can only 283 be prepared at concentrations in the $\mathrm{mg} / \mathrm{L}$ range if made in de-ionized water. Assuming that fully 
284 dispersed ENP powders are a worst case scenario for hazard testing, the stock concentrations need 285 to ideally be as low as possible to avoid/minimize particle agglomeration and as close to the highest 286 tested concentration as possible without producing artefacts due to dilution of test media. However, 287 'stable' non-agglomerating particle concentration regions need to be established on a case-by-case 288 basis. If dispersions are prepared using stabilizing agents and/or $\mathrm{pH} /$ ion-strength optimization, then 289 sufficiently stable dispersions may be made for notably higher concentrations. Achieving a good 290 dispersion at the highest possible concentrations would naturally be facilitated by tailoring each 291 medium and preparation technique for the specific ENP. However, such an approach does not result 292 in harmonization. Although pure water could often be the immediate preferred choice of medium, 293 it may not enable the required doses for neither in vitro nor in vivo toxicological testing. protocol pre-wetting with $\mathrm{DI}$ water is recommended for $\mathrm{CeO}_{2}$. This procedure might be advantageous for ENP, which are hydrophilic, but appear as dense agglomerates, or form soft

\section{Pre-wetting of ENP powders}

Hydrophobic ENP present a challenge in the preparation of aquatic dispersions. A 'pre-wetting' step is included in some dispersion procedures to facilitate dispersions of these ENP. The hydrophobicity of a ENP may either stem from surface chemistry such as coatings or functionalization or from its inherent atomic surface structure such as honeycomb structure of carbon nanotubes (CNT) and is generally enhanced by nano-scale surface roughness (Li et al., 2002).

A pre-wetting step (i.e. making a paste of the powder ENP by mixing it with a liquid) is prescribed in many of the reviewed dispersion protocols. Pre-wetting has the purpose to overcome the hydrophobicity of the 'native' ENP by changing its surface properties. In the PROSPEcT bridging, or have large and maybe even reactive surface areas. In these cases, increased dispersion 
308 may possibly be reached by increasing reaction time with water before sonication. In other 309 reviewed protocols the pre-wetting is undertaken with a $0.5 \mathrm{vol} \%$ ethanol solution (Table 1 ). 310 Different techniques, water and/or solvents might be applied depending upon the material. The 311 purpose in the initial step is to assist de-agglomeration of specific ENP. This process may require a 312 hydrophilic solvent and/or a solvent with a lower surface tension compared to that of water. The 313 surface tension of ethanol is $\sigma=0.02 \mathrm{~N} / \mathrm{m}$ as compared to that of water $0.07 \mathrm{~N} / \mathrm{m}$ and ethanol is also 314 hydrophilic. General use of ethanol would therefore in general improve the initial dispersion of both 315 agglomerates and hydrophilic compounds. When subsequently dispersed in water the pre-wetted 316 particles may be more easily dispersed, and ethanol can be evaporated if sufficient heating, 317 sonication or time is applied. However, if evaporation is incomplete, the presence of ethanol in the 318 dispersion might potentially affect subsequent experimental results by producing adverse effects 319 on the test organisms (Caro \& Cederbaum, 2004; Brown \& Brown, 2012). To prevent this it is thus 320 important to ensure proper evaporation of the solvent.

321 In the ENPRA protocol pre-wetting is applied as a standard procedure for ZnO ENP, 322 independently of hydrophobicity of the tested ENP, for the sake of full comparability in 323 comparative testing. In the more generic NANOGENOTOX dispersion protocol it is applied to all 324 ENP to ensure full comparability across a wider set of test materials. This represents a trade-off 325 between comparability and minimizing modifications of test material and thereby potential 326 artefacts. It may, however, be a necessary inclusion for harmonization across different ENP.

327 It is still difficult to conclude whether general pre-wetting using chemicals other than water 328 should be recommended for harmonized dispersion protocols. The critical issues are whether the 329 chemical used for pre-wetting significantly changes relevant physicochemical ENP properties or the 330 compound in itself or by degradation products may induce important biological side-effects. For the 3310.05 vol\% ethanol concentrations used in the ENPRA, NANOGENOTOX and PROSPEcT, such 
332 effects are still not observed or reported. One could decide, as in the ENPRA procedure, that pre333 wetting is only applied when necessary. In any case it is important, and already normally applied in 334 toxicological studies, to include media control to incorporate such effects into account. This 335 procedure, however, does not enable control over potential changes to the test material where a 336 specific concern would be changes in chemical surface coatings.

337

338

\section{Dispersion medium composition}

Given the diversity of aquatic media that can be used for dispersion preparation, specification of the individual ingredients in the stock dispersion media and their qualities is a key for harmonization. Media composition is known to influence ENP behavior in a complex manner, for example as a result of ion composition and ionic strength (Ottofuelling et al., 2011). The requirements for a stock dispersion media include (1) simplicity for predictability of particle behavior, and (2) compatibility with biological assays. As the stock dispersion is subsequently diluted into a test media or test matrix the stock dispersion media does not need to contain the nutrients necessary for survival of the test organisms. However, the constituents of the stock media should not have a negative biological effect.

Pure water was selected as the foundation in all reviewed protocols presented in Table 1 . The two main criteria are specified with regards to purity, as determined by resistivity, and bacterial contamination as indicated by the presence of endotoxins. The resistivity criteria have been defined to ensure high purity of the water as water-resistivity depends on its ion content. Higher ion content, caused by impurities, leads to a higher conductivity and hence lower resistivity. Water is considered pure when its resistivity is above $18.2 \mathrm{M} \Omega \cdot \mathrm{cm}$ at $25^{\circ} \mathrm{C}$. High purity water does usually not improve the dispersion of ENP, but is requested to avoid unpredicted/uncontrolled variations in stability and toxicological effects due to variable water chemistry. 
356 Microbial purity is another highly important criterion in dispersion protocols. Bacterial 357 contamination, or presence of other bio-colloids, may be a critical factor in ENP dispersion, due to 358 the potential hetero-aggregation of particles and bacteria (Hotze et al., 2010), production of 359 exudates, and biological degradation of organic surface coatings, which in turn affect dispersion 360 properties. However, more importantly for toxicological testing, presence of bacteria might initiate 361 strong toxicological responses. The reviewed protocols (Table 1) specify the absence of bacterial 362 contamination which is indicated by the concentration of lipopolysaccharides / endotoxins as given 363 in $\mathrm{EU} / \mathrm{ml}$, where $1 \mathrm{EU} / \mathrm{ml}$ is approximately 0.1-0.2 $\mathrm{ng}$ endotoxin/ml (Ryan, 2004). It should be 364 noted that, while bacterial and other microbial contamination may be removed by filtration, 365 endotoxins could still be present and would require additional treatment. Some protocols provide 366 specific limit values for levels of lipopolysaccharides / endotoxins in water. Three protocols 367 (ENPRA, NANOGENOTOX and PROSPEcT) prescribe filtration through a filter with a $\leq 0.45 \mu \mathrm{m}$ 368 pore size, which is considered to retain microorganisms and produce sterile water. To reduce 369 changes in dispersion properties due to water chemistry or bacterial contamination, and to make 370 stock dispersion compatible with a subsequent use in a variety of biological tests, it is generally 371 recommended to use high quality, ultrapure water with a resistivity of above $18.2 \mathrm{M} \Omega \cdot \mathrm{cm}$ in ENP 372 stock dispersion protocols.

\section{pH and medium composition}

374 ENP dispersions can also be stabilized through increasing the electrostatic stabilization as a 375 result of the charges from the electric double layer. These charges might either be negative or 376 positive, depending on the $\mathrm{pH}$ of the medium they are found in. There also exists a $\mathrm{pH}$ at which 377 these charges are neutral and this point is called the isoelectric point, or point of zero charge. It is 378 here where the electrostatic repulsion is non-existent and that ENP are more prone to 379 agglomeration. Therefore, $\mathrm{pH}$ is an important parameter in dispersion stability. 
380 While various studies (Badawy et al., 2010; Domingos et al., 2013; Zhu et al., 2014) used the 381 parameter of $\mathrm{pH}$ to stabilize suspensions in media, few studies employed $\mathrm{pH}$ to control dispersion of 382 ENP stock suspensions for toxicological studies (Cupi, 2015), although similar principles apply. 383 Stability of $\mathrm{TiO}_{2} \mathrm{P} 25 \mathrm{ENP}$ dispersed in high purity water water was assessed at $\mathrm{pH} 4,6$ and 8 . The 384 isoelectric point was around 5, and most stable suspensions with regards to particle sizes and zeta 385 potential were those at $\mathrm{pH} 8$, which was the furthest away from the isoelectric point (von der 386 Krammer et al. 2010). Similar results were observed for $\mathrm{TiO}_{2} \mathrm{P} 25$ where the isoelectric point was 387 around 6, when $\mathrm{pH}$ was adjusted to 3,5.9, 7, 9 and 11 . The smallest agglomerates occurred in $\mathrm{pH} 9$ 388 and 11 (Horst et al 2012). Cupi (2015) observed the stability of $\mathrm{Ag}, \mathrm{ZnO}$ and $\mathrm{TiO}_{2} \mathrm{ENP}$ in high 389 putity (MilliQ-filtered) water, Elendt M7 medium, Very soft (VS) EPA medium and Soft (S) EPA 390 over $\mathrm{pH}$ values 2-12. For all three ENP, lowest sizes could be achieved in high purity water, but $\mathrm{pH}$ 391 values where the suspensions were more stable depended upon the particle. Agglomeration 392 increased with a rise in ionic strength of the media and was highest for Elendt M7 medium. For 393 suspensions to be used for toxicological studies, Guiot and Spalla (2013) determined that 394 measuring the isoelectric point of 4 different $\mathrm{TiO}_{2}$ ENP is important, but in case of addition of a 395 stabilizing agent, $\mathrm{pH}$ of that agent also needs to be taken into account. Addition of BSA at neutral $396 \mathrm{pH}$ might initiate rapid aggregation due to interactions of almost neutral ENP and negatively 397 charged BSA.

398 Identification of the isoelectric point for the each suspension seems to be a fundamental step 399 when preparing stock suspensions, allowing for an evaluation of particle behavior over a range of $400 \mathrm{pH}$ values and identification of most stable and physiologically relevant conditions.

\section{Ultrasonication procedure}


402 The dispersion of dry ENP powder in aqueous medium is most often facilitated by sonication, 403 applying sound energy with ultrasonic frequencies to the dispersion. Other methods include 404 magnetic stirring, vortexing, and shaking. While these are less aggressive methods, they are also 405 less efficient in dispersing ENP. A variety of sonicator types are available, which differ in 406 efficiencies and in the manner in which energy is delivered to the sample. Some of the most 407 common types are probe sonicators (direct), bath sonicators (indirect), and less commonly used cup 408 horn sonicator. Some advantages and disadvantages of different sonication apparatus are 409 summarized in Table 2. Sample contamination may occur when probe sonicating different samples 410 consecutively or from trace metal release due to erosion of the probe tip (usually made from 411 titanium). Using a silica (glass) probe tip (sonotrode) might reduce this risk. This, however, requires 412 a reduced amplitude (IMLAB, 2013) and results in a reduction of delivered effective energy and 413 sonication efficiency. It is also noteworthy that dispersion protocols specify careful cleaning of the 414 probe-sonicator between samples and that the potential cross-contamination is low when the stock 415 dispersion are present in $\mathrm{g} / \mathrm{L}$ concentrations. A cross-contamination of $10 \mu \mathrm{g}$ into $2.56 \mathrm{mg} / \mathrm{ml}$ in 6 $416 \mathrm{ml}$ would result in less than $0.065 \mathrm{wt} \%$ contamination, which usually would be further diluted in the 417 experiment. Bath sonication, on the other hand, has a major drawback from a harmonization point 418 of view, as it is practically impossible to accurately control the effective energy delivered to the 419 sample as it is not delivered directly into the sonicated sample. The effective energy delivered to the 420 sample is lower for bath sonicators compared to probe (and cup horn) sonicators, making them less 421 efficient from a dispersibility point of view (Jiang et al. 2009; Franklin et al. 2007; Caneba et al. 422 2010; Mejia et al. 2012).

423 In a sonication device the input power, i.e. the electrical energy consumed by the device, is 424 converted to high frequency energy pulses usually given in $\mathrm{Hz}$, number of pulses per sec, which is 425 then transformed into mechanical vibrations as in a probe with a certain amplitude equal to the 
426 distance of probe movement resulting in the formation of microscopic waves. This process results 427 in an output of acoustic power (W) with an certain intensity $\left(\mathrm{W} / \mathrm{cm}^{2}\right)$ per ultrasonic source surface 428 unit such as probe tip surface area (Capelo-Martínez, 2008). This can again be described as a local 429 energy density $(\mathrm{W} \cdot \mathrm{sec} / \mathrm{ml})$, defined as "the amount of delivered energy per unit of suspension 430 volume", meaning that at equal particle concentration and power, "higher energy densities (i.e., 431 lower dispersion volumes) will result in a greater disruptive effect" (Taurozzi et al, 2012b). As 432 indicated by Taurozzi et al. (2011) the efficiency of the energy transformation from the electrical 433 input power to the acoustic power effectively received by the sonicated dispersion depend 434 predominantly on the specific sonication device. Therefore, simply reporting the displayed input 435 power and sonicator settings does not accurately reflect the actual energy delivered to the sample 436 and hence accounting for lack of reproducible results (Taurozzi el al., 2011). However, as 437 illustrated by the case studies presented in Table 1, sonication power, settings and probe dimensions 438 are the parameters normally specified in the dispersion protocols considering that similar types of 439 probe sonicator would be used. In reality many different types of sonicators are available in 440 different probe designs, powers, frequencies, and range in amplitudes. The challenge is to develop a 441 calibration method that is widely applicable. In preparation of the final NANOGENOTOX protocol, 442 however, the consumed energy at the fixture was used for calibrating the delivered energy of 443 different types of sonicators. The resulting average particle size was found to decrease as a power 444 function of sonication time for all applied sonication instruments, resulting in comparable particle 445 sizes at the same delivered energy (Jensen et al., 2011b).

446 Calibration of different probe sonicators is a key issue. Some probe sonicators read out the 447 delivered energy dose given to the sample, but this feature is not available in all sonicators and data 448 may not be directly comparable. Different methods exist to calculate the effective energy delivered 449 to the sample including calorimetric methods based on temperature increase (Taurozzi et al., 2012b) 
450 and methods based on measured power consumption during working and no-load operation such as 451 sonication of dispersion and air, respectively (Bihari et al., 2008). In the ENPRA project 452 harmonization was attempted by using the same brand and make of sonicator. In the 453 NANOGENOTOX project different sonicators were used and calibrations were performed to 454 determine the amplitude and durations based on the consumed energy measured using a Watt-meter 455 at the wall-fixture combined with performance testing on an internal common material and 456 benchmark data on hydrodynamic size-distributions on all test materials (Jensen et al. 2011c). Other 457 and more specific methods for harmonization include measurement of the amount iodide to iodine $458\left(\mathrm{E}_{0}=-0.615 \mathrm{~V}\right)$ conversion by oxidation according to the Weissler reaction during sonication. 459 However, this procedure also has some quantitative limitations due to sensitivity to temperature and 460 some reactivity without hydrodynamic cavitations (Morison and Hutchinson 2009), which need to 461 be understood with respect to specific use.

462 Reproducibility in preparing ENP dispersions by sonication requires consistency at least in 463 effective energy delivered to the sample ${ }^{1}$, the vials used, temperature, medium viscosity, particle 464 concentration and sample/vessel volume. For probe sonication also the shape and diameter of the 465 probe, as well as probe immersion depth is important. Smaller sample vessel diameters and an 466 immersion depth of 2-5 cm was recommended for standard probes (Taurozzi et al., 2011). Based 467 upon existing data, it appears that comparable and reproducible results can be made using probe 468 sonication and that this is a practical, accessible and pragmatic choice for harmonization of 469 dispersion protocols, whilst acknowledging that further optimization and guidance is needed.

470 To reach one or a set of harmonized dispersion protocols it is necessary to establish standard 471 procedures for determining and calibrating the specific delivered energy and de-agglomeration 472 efficiency of sonicators combined with a standardized reporting requirement. Development of such

\footnotetext{
${ }^{1}$ A sample is here defined as dispersion of nanomaterials including any additives
} 
473 a method for calibration, combined with detailed reporting of sonication procedure information, 474 would greatly improve interpretability, comparability and reproducibility. As a starting point for 475 reporting requirements the list of sonication parameters in (Taurozzi et al., 2011; 2012a) could be 476 consulted, where the latter also includes more general reporting requirements for preparation of 477 ENP dispersions.

478 During sonication the reactive species produced during cavitation and heating of the sample 479 may directly produce modifications and degradation of ENP, dispersants, coatings and/or media 480 components. Heating would have additional importance in evaporation if high energies or long 481 sonication times are used. A cooling coil might be mounted in the bath sonicators water bath. For 482 probe sonication cooling might be done by placing the sample in an ice-water bath (or ice-salt bath) 483 (Table 1) which the transfer of heat (cooling of the sample) might be optimized by increasing the 484 vessel wall-surface-to-volume ratio. In addition, pulsed mode sonication, in which the sonicator 485 operates at alternated on/off intervals, might aid in minimizing heating of the sample and thus 486 improve temperature control (Taurozzi et al, 2012b). However, this mode is not available in all 487 sonicators, which has been a limiting factor in development of the procedures discussed here.

488 If the ENP dispersion is to be used in biological testing then knowledge of possible influences 489 of sonication procedures on toxicity is of vital importance for interpretation of experimental results. 490 As indicated by Taurozzi et al. (2011) sonication leads to formation of reactive species ('sonic 491 activation') during cavitation. An increased toxicity of ENP dispersions after sonication may 492 theoretically be explained by formation of radical species such as thermal dissociation of water into $493 \cdot \mathrm{OH}$ radicals and $\bullet \mathrm{H}$ atoms (Riesz and Kondo, 1992) and subsequent recombination into hydrogen 494 peroxide (Brown and Goodman, 1965), which may interact with ENP and change its surface 495 chemistry (Taurozzi et al. 2011). Oxidation is practically inevitable during sonication and may 496 produce some limitations in testing acute effects of materials with elements in reduced state. 
497 Further, sonication may generate the formation of toxic degradation products of dispersants or other 498 media constituents (Wang et al., 2012), change surface coating chemistry (Taurozzi et al., 2011), 499 enhanced release of metal ions or increased toxicity due to smaller particle sizes (Cronholm et al., 500 2011). A few studies compared the biological effects of ENP dispersions when prepared by use of 501 stirring, bath sonication and probe sonication (Table S1 in SI). The general trend is an enhanced 502 toxicity of bath and probe sonicated ENP dispersions compared to non-sonicated dispersions such 503 as stirred. However, as studies vary in test organism, test material as well as sonication type and 504 settings, such as frequency or time, it is not possible to make any direct comparison. Overall, due to 505 known possible sonication-induced modifications to ENP and their biological reactivity it is 506 recommended to only apply the minimum energy input required to obtain a disperse particle 507 dispersion.

\section{Dispersants}

510 A challenge for accurate exposure and dosing in (eco)toxicological testing of dispersed ENP 511 powders is related to their different agglomeration and aggregation (or 'bundling' in the case of 512 CNT). In principle, the interactions between ENP in dispersion (or in general between two 513 interfaces in a dispersed system) may be described by the DVLO theory, named after Derjaguin, 514 Landau, Verwey, and Overbeek (Chen and Elimelech, 2007; Feiler et al., 2000). In brief, the overall 515 interaction energy between two interfaces is the net balance of the repulsive electrostatic Coulomb 516 (double layer interaction) forces and the attractive van der Waals forces. The overall force 517 determines whether ENP in aqueous media form stable dispersions or agglomerates (Salager, 1994). 518 In order for CNT bundling to occur strong van der Waals interactions are required along the tube 519 hampering their dispersibility (Edri and Regev, 2008). In order to enhance the dispersibility and 520 stability of ENP in aqueous media various dispersants might be added to overcome the attractive 
521 forces through increased steric repulsion. A division may be made between natural dispersants 522 including proteins and humic acids and synthetic dispersants such as poloxamers or other non-ionic 523 surfactants (Handy et al., 2012a). When adding dispersants, modifications of biological response(s) 524 is a general concern resulting from inherent toxicity or antioxidant properties of the surfactant as 525 well as hampering the direct interactions between the ENP and biological surfaces. Wang et al. 526 (2010a) noted a dispersant should not induce toxic effects in itself and at the same time neither 527 mask nor enhance the biological activity of the ENP. Biological relevancy and testing regime are 528 also important factors to consider. It is of interest that Thomas et al. (2011) reported that serum 529 protein and natural organic matter (NOM) have been suggested as the most promising choice of 530 dispersants for human and environmental toxicity studies, respectively. This has already been 531 implemented in the CEINT / NIST dispersion protocol (Table 1).

\section{Serum proteins}

533 In in vitro and in vivo toxicity testing, biological dispersants are often highly favored over 534 synthetic chemicals. Certain serum proteins, such as bovine serum albumin (BSA), were found to 535 efficiently aid dispersion of some ENP in toxicity testing media. Kim et al. (2011) examined CNT 536 dispersion efficiency and biocompatibility as evaluated by toxicity testing using trypan blue dye 537 exclusion, lactate dehydrogenase (LDH) leakage, and neutral red assays using following 538 dispersants: 0.5\% BSA, dimethylsulfoxide (DMSO), 1,2-dipalmitoyl-sn-glycero-3-phosphocholine 539 (DPPC) and 1\% Tween 80. All 4 dispersants were found to be biocompatible in the sense of not 540 inducing cytotoxic effects. Their efficiency as dispersants was observed to depend on the type of 541 CNT, i.e. SWCNT or MWCNT. The stability of the dispersions was monitored over 16 weeks and 542 the following descending order from more stable to less stable was established: BSA $>$ Tween $80>$ 543 DPPC $>$ DMSO for MWCNT and BSA $>$ DPPC $>$ Tween $80>$ DMSO for SWNCT (Kim et al., 544 2011). Although this indicates that dispersants may have to be chosen based on the material to be 
545 dispersed, data also indicate that BSA seems to be an efficient dispersant for CNT. BSA also 546 efficiently improved the dispersibility of $\mathrm{TiO}_{2}$ ENP in different cell culture media, for which 547 phosphate concentration was determined to be a key factors governing variations in ENP dispersion 548 between different media (Ji et al., 2010). Conformation of the BSA protein, which is $\mathrm{pH}$ dependent, 549 was found to influence CNT dispersion efficiency (Edri and Regev, 2008). To enable dispersion of $550 \mathrm{TiO}_{2}$, a required ratio between serum albumin and ENP concentrations was determined by Bihari et 551 al. (2008): $\mathrm{TiO}_{2}$ in a concentration $<0.2 \mathrm{mg} / \mathrm{ml} \mathrm{might} \mathrm{be} \mathrm{stabilized} \mathrm{by} \mathrm{addition} \mathrm{of} 1.5 \mathrm{mg} / \mathrm{ml}$ serum 552 albumin from human, mouse or bovine, corresponding to approximately $0.15 \mathrm{vol} \%$ depending on 553 serum density. The method was found to be applicable resulting in dispersions with agglomerate 554 average diameter $<290 \mathrm{~nm}$ for the following $\mathrm{ENP}: \mathrm{TiO}_{2}$ (rutile), $\mathrm{ZnO}, \mathrm{Ag}, \mathrm{SiO}_{2}, \mathrm{SWNT}, \mathrm{MWNT}$, 555 and diesel SRM2975 particulate matter. In comparison, 2 vol\% serum is prescribed for the 556 PROSPEcT and ENPRA protocols for dispersing ENP at a concentration of $2.56 \mathrm{mg} / \mathrm{ml}$, whereas 557 only $0.05 \mathrm{wt} \%$ sterile-filtered BSA-water is recommended for the same particle concentration in the 558 NANOGENOTOX protocol (Table 1). In both ENPRA and NANOGENOTOX dispersion 559 protocols, the amounts required were based on titration to identify the common best dispersant 560 concentration for $\mathrm{TiO}_{2}(\mathrm{NM}-101)$ and MWCNT (NM-400) and subsequently documented for other 561 ENP to be used in these projects. In addition to BSA other types of serum proteins used for 562 dispersing ENP have been investigated or used, including human serum albumin, mouse serum 563 albumin, mouse serum (Bihari et al., 2008), fetal bovine serum (Ji et al., 2010) and Survanta ${ }^{\circledR}$ 564 natural lung surfactant (Wang et al., 2010a), 10\% BAL (bronchoalveolar lavage) fluid from sibling 565 mice mixed into MilliQ-filtered high purity water with $0.9 \% \mathrm{NaCl}$ (Jacobsen et al., 2009).

$566 \quad$ Natural organic matter

567 Natural organic matter (NOM) is a complex matrix of organic materials that plays an important 568 role in the aquatic environment (Sillanpää, 2015). The composition of NOM varies depending on 
569 environmental factors and biological processes but generally contain a large fraction of hydrophobic 570 acids such as humic acids (HA) and fulvic acids (FA). HA and FA differ in water solubility, 571 molecular weight, functional group distribution and elemental composition (Sillanpää, 2015). These 572 substances are large molecules containing hydrophilic and hydrophobic parts including aromatic 573 rings and functional groups such as carboxyls and hydroxyls (Kördel et al. 1997). These structures 574 give NOM a good complexation capacity where various pollutants/metals may bind. Therefore, 575 NOM play a major role in mobility of contaminants through the process of adsorption, aggregation 576 and sedimentation (McCarthy and McKay, 2004), and in bioavailability of metals (Buffle and van 577 Leeuwen, 1992). Due to this property, NOM were shown to act as a stabilizing agent for colloids 578 under certain conditions (Tiller \& O'Melia 1993; Wilkinson et al. 1997), and during the last decade, 579 various forms of NOM were also employed to stabilize and control dispersions of ENP. The most 580 commonly used forms of NOM in ecotoxicological research of NP include commercial and isolated 581 HA and FA, and NOM containing different amounts of HA and FA such as the Suwannee River 582 natural organic matter (SR-NOM). NOM addition to ENP dispersion before sonication has been the 583 common practice in most studies.

585 NOM has been widely used to stabilize a variety of ENP in test medium (Akaighe et al., 2012; 586 Baalousha et al., 2013; Domingos et al., 2013) but only a few studies have used it to stabilize stock 587 suspensions (Cupi, 2015). Manier et al. (2011) investigated the effect of HA on the stability of $588 \mathrm{CeO}_{2}$ ENP in stock dispersions prepared in high purity water and different synthetic freshwater 589 media. NOM has been used to stabilize stock suspensions of metal (Ag) and metal oxide ( $\mathrm{ZnO}$, $590 \mathrm{TiO}_{2}$ ) ENP (Cupi et al., 2015). Coating of the ENP with NOM leads to steric and electrostatic 591 repulsion as well as formation of a negative surface charge on the NP, which assist in stabilizing NP 592 dispersions. However, at high NOM concentrations bridging might occur which result in 
593 sedimentation. HA adsorption to metal oxide ENP has mostly been attributed to electrostatic 594 interaction and ligand exchange (Yang et al. 2009). In test media, SR-NOM and SR-HA (15 mg/L) 595 (Akaighe et al. 2012), and SR-FA (5 mg/L) (Baalousha et al. 2013) were found to produce 596 stabilization of Ag NP at low ionic strength media. Despite the stabilization effect, an important 597 parameter to keep in mind is the implication of NOM presence in the biological effects of the ENP. 598 Presence of NOM reduced the toxicity of Ag NP towards Japanese medaka embryos in dispersion 599 most likely due to coating of NP and decreasing the release of ions (Kim et al. 2013), and/or 600 complexation with $\mathrm{Ag}^{+}$present in the solution (Kim et al. 2013; Gao et al. 2012a). Increasing 601 amounts of NOM were also associated with reduced amounts of $\mathrm{Zn}^{2+}$ released from $\mathrm{ZnO}$ ENP (Li et 602 al. 2013). Previous studies revealed that agglomeration on ZnO ENP was highly dependent on 603 NOM concentration (Zhou and Keller 2010, Domingos et al. 2013). SR-NOM concentrations of 20 $604 \mathrm{mg} / \mathrm{L}$ were able to decrease agglomeration in ZnO nanoparticles (Domingos et al. 2013). Zhou and 605 Keller (2010) noted that SR-NOM in concentrations $>10 \mathrm{mg} / \mathrm{L}$ increased the stability of the test 606 system. Humic substances such as SR-HA at 0.2-5 mg/L (Domingos et al. 2009) or $10 \mathrm{mg} / \mathrm{L}$ (Thio 607 et al 2011) were also shown to stabilize $\mathrm{TiO}_{2}$ ENP dispersions. Four mg/L SR-NOM was found to 608 reduce aggregation of $\mathrm{TiO}_{2}$ in dispersion (Zhang et al. 2009). Similar to test suspensions NOM 609 might also exert an influence on stability of stock suspensions. The affinity of NOM to different 610 ENP depends on chemical composition, chemical structure and present capping agents. 611 Stabilization depends upon type of NOM and concentration; therefore, use of NOM for stabilizing 612 dispersions of different ENP needs to be performed in a case-by-case basis.

\section{Poloxamers}

614 Polaxamers is a group of non-ionic polymers which are widely used as ENP dispersants (Wang 615 et al., 2012). In the NANOMMUNE stock dispersion protocol 160 ppm Pluronic F126 is added to 616 facilitate dispersion of CNT but not for other ENP (Table 1). The implications of poloxamer 
617 degradation during sonication and subsequent consequences of potential degradation products for 618 biological effects was examined by Wang et al. (2012). This study focused on dispersions of 619 MWCNT using two representative Pluronic surfactants (F-68 and F-127), which are commonly 620 used in dispersing carbon-based ENP. As an alternative to the Pluronic surfactants, the study 621 compared results to dispersions prepared with BSA as dispersant. It was found that the dispersions 622 prepared with Pluronic surfactants became highly cytotoxic after probe as well as bath sonication 623 both in the presence and absence of MWCNT, and depended on sonication time, power, and 624 frequency. This was not the case when BSA was used in dispersing the MWCNT (Wang et al., 625 2012). Evidence indicates that if poloxamer dispersants are used they need to be added after the 626 sonication step to avoid potential production of toxic degradation products; however, the use of 627 alternative to poloxamers dispersants needs to be considered when possible.

\section{Other dispersants}

629 In addition to the already mentioned dispersants other materials have also been added to 630 increase the dispersibility of ENP in aqueous media. Gao et al. (2012b) investigated dispersion 631 methods for carbon-based ENP for ecotoxicity testing. The toxicity of a number of surfactants and 632 tetrahydrofuran (THF) were assessed for their ecotoxicity to green algae $P$. subcapitata and 633 crustacean $C$. dubia. The surfactants include polyvinylpyrrolidone (PVP), gum arabic (GA), sodium 634 dodecylbenzenesulfonate (SDBS), sodium dodecyl sulfate (SDS), sodium cholate (Na-cholate), 635 Triton X-15 and Triton X-100. Based on ecotoxicity studies it was found that Triton X-15, PVP, 636 GA exerted no significant negative impacts on growth of $P$. subcapitata in concentrations up to $6371,000 \mathrm{mg} / \mathrm{L}$. Lack of adverse effects to C. dubia was only seen for PVP and GA. Hence from an 638 ecotoxicological point of view PVP and GA might be proposed as appropriate surfactants for 639 general ENP dispersion protocols. However their suitability over a range of particle types and 640 toxicity towards different organisms requires further clarification. At the same time potential 
641 stimulating effects of surfactants also need to be considered. GA is a complex plant exudate with 642 antioxidant properties and was found to enhance growth of $P$. subcapitata compared to control (Gao 643 et al., 2012b). In past studies the use of THF in ENP dispersions for ecotoxicity studies was found 644 to be controversial (Oberdörster, 2004; Zhu et al., 2007; Henry et al., 2007). It has been established 645 that toxic transformation products are formed from THF oxidation causing toxicity artefacts (Henry 646 et al., 2007). Data indicate the need for appropriate controls to monitor negative as well as positive 647 effects of dispersants on test organism responses.

648

TOWARDS HARMONIZED DISPERSION PROTOCOLS

650 In the quest of selecting or further developing stock dispersion protocols for ENP it is 651 important to clarify the intended use and purpose of such protocols. For in vivo studies, it is 652 important that ENP is well-dispersed and that the vehicle is biologically relevant for the intended 653 exposure route and toxicological evaluations whether they be in vivo or in vitro. For in vitro and 654 aquatic ecotoxicological studies, it could be argued that reaching stable stock dispersions is not 655 essential, because stock dispersions are often diluted in complex media prior to biological testing. 656 Here ENP behavior will anyway change dramatically and stability achieved in the stock dispersion 657 is lost. However, it is postulated that use or further development of appropriate and harmonized 658 stock dispersion protocols is important to:

659 - Minimize test artefacts: if ENP are heavily agglomerated in the stock dispersion, the 660 agglomeration state may be 'transferred' to the test media where agglomeration may 661 increase further. Further, inappropriate dispersion methods might induce other test artefacts 662 by modifying ENP properties.

663 - Ensure quality control: by developing appropriate and transparent dispersion protocols test 664 artefacts may be further minimized and retrospectively evaluated. 
- Facilitate data comparability: comparability in initial dispersion characteristics may be attained and issues related to stock dispersion preparation is not a confounding factor when comparing results between tests. By not harmonizing stock dispersion procedures an concern. additional level of uncertainty is added.

- Enable future quantitative structure-activity relationship (QSAR) model developments: using common dispersion protocols for testing ENP properties including physico-chemical properties, fate and (eco)toxicity might provide more coherent datasets with the possibility of making direct links between outcomes of different tests and ENP properties.

- Allowing for establishment of quality criteria: development of technical guidance for ENP dispersion infers that quality and validity criteria are established for the properties of the resulting dispersion such as dispersion stability and state of dispersion.

It needs to be recognized that reaching harmonization and standardized protocols will always be a compromise between optimum dispersion on one hand and optimum biological/ physiological and material compatibility of the medium and concentrations required in the stock dispersion on the other hand. The advantages and disadvantages of strict harmonization and full flexibility are illustrated in Figure 1. Generic protocols, such as ENPRA and NANOGENOTOX dispersionprotocols, are highly relevant for regulatory testing providing the ability to compare test results more directly, whereas tailored dispersion protocols may be more applicable to scientific research questions where the ability to compare between different test results may be of less

The extent of harmonization, case-by-case adaptation and flexibility are issues that require attention when a specific dispersion protocol is selected or developed, to avoid the situation that a generically optimized protocol is applied to a specific particle type, for which it is unsuitable producing either false positive or false negative toxicological results. Hence, some mechanism is 
689 needed within a general protocol to detect and deal with exceptions through specification of 690 performance criteria. Therefore, there is an urgent need to critically evaluate already existing 691 protocols for their general applicability or domain of applicability (type(s) of ENPs, all or specific 692 bioassays).

Based on the information collected through this review, a step-wise approach for developing a 694 tailored dispersion protocol is proposed in Figure 2. This figure highlights the information required 695 and typical points of decision to establish a new or evaluate an existing ENP dispersion protocol. In 696 the first step, the purpose of the experiment/test and intended assay (testing regime such as 697 ecotoxicological or mammalian test system) needs to be clarified with information on the intended 698 exposure route (Figure 2). In addition, performance criteria need to be considered (for example 699 what is considered an acceptable criterion for stability). This is the basis for the choices made in the 700 development of the dispersion protocol. While the step-wise approach shown in Figure 2 describes 701 development of a tailored dispersion protocol for one ENP or a group of ENP, the same steps are 702 required to be considered in a more generic dispersion protocol. However, where a tailored 703 dispersion protocol may be driven by specific performance criteria such as whether stable and well704 dispersed dispersions are obtained or no further dispersion efforts are needed, a generic protocol is 705 driven by general performance criteria that all ENP, for which the protocol is considered applicable, 706 will be relatively well dispersed.

707 As shown in Figure 2, the first steps in development of a tailored dispersion protocol involve 708 collecting basic information on ENP including data particle composition, coating, solubility and 709 hydrophobicity. This information enables informed choices in the subsequent steps of the 710 dispersion protocol. A choice of suitable stock concentration is then made. Ideally this needs to be 711 low as possible to minimize particle agglomeration while at the same time taking into account the 712 concentration requirements in the subsequent tests, for which the dispersion is being prepared. . The 
713 hydrophobicity of the material determines the need for pre-wetting, which is usually done with 714 ethanol although other pre-wetting solutions may also be considered. In case of pre-wetting 715 relevant controls need to be considered and complete evaporation of the pre-wetting agent is 716 required to be ensured. As illustrated in Figure 2 ENP is now mixed into water for which certain 717 quality criteria are defined in the protocol. It is recommended that high quality, ultrapure water 718 with a resistivity of $18.2 \mathrm{M} \Omega \cdot \mathrm{cm}$ in ENP stock dispersion protocols be employed. The mixing 719 procedure needs to be described explicitly in the protocol as it may influence the resulting 720 dispersion. If the dispersion is not stable upon mechanical mixing, sonication needs to be applied, 721 where probe sonication is considered the most practical, accessible and pragmatic choice from a 722 reproducibility and harmonization point of view. To avoid heating of the sample it is required to be 723 placed in a water bath or ice-water bath during sonication with temperature to be monitored to 724 ensure stable conditions. Sonication time needs to be selected to minimize the energy input, 725 reducing risk of ENP modifications, while still obtaining a disperse particle dispersion. Appropriate 726 sonication controls need to be included to ensure that the ENP is not modified due to this procedure 727 and that no toxic sonication products are formed. Reporting requirements are needed for a detailed 728 description of the sonication procedure including information on specific energy delivered to the 729 sample. If this is still not sufficient to ensure a stable dispersion, different dispersants are required to 730 be considered. The specific choice of dispersant may depend on the testing regime and biological 731 relevancy with serum protein and NOM as common choices for human and environmental toxicity 732 studies, respectively. However, other alternatives exist. An ideal dispersant would aid dispersion 733 stability over a range of particle types, be non-toxic and neither mask or enhance biological activity 734 of the ENP. A suitable dispersant concentration needs to be specified while taking into account that 735 higher concentrations may be counter effective on dispersibility due to bridging. As for pre-wetting 
736 and sonication, it is important to include controls that capture possible test artefacts induced by 737 dispersants as a result of ENP transformations or modifications.

\section{DISCUSSION}

Several dispersion protocols have already been developed and are used for specific ENP or 740 groups of ENP and biological test systems. However, to ensure the appropriateness of a harmonized 741 dispersion protocol several issues were identified that urgently require additional clarification. 742 Sonication plays critical role in the dispersion preparation, but also represents a key challenge. It is 743 not feasible to give one general recommendation on the sonication procedure that applies to all 744 ENP. It is evident that the higher sonication energy the greater risk of partial oxidation of the ENP 745 and degradation of organic coatings, functionalization and maybe even changes in the structure of 746 compounds such as CNT. From a reproducibility and harmonization point of view it is proposed to 747 use moderate probe sonication as a practical, accessible and pragmatic choice, whilst 748 acknowledging that optimization and additional guidance is needed to optimize and harmonize the 749 procedure between labs. Some guidance on this is offered by Taurozzi et al. $(2011 ; 2012 a)$, which 750 also include suggestions for reporting procedures. However, ways of measuring and reporting the 751 energy effectively delivered to the dispersion and control the effective de-agglomeration efficiency 752 need to be further elaborated to make them practically and routinely applicable. Theoretically, 753 minimizing energy input from sonication may serve to minimize artefacts in biological tests. 754 However, no studies have been identified, which systematically investigate links between 755 sonication procedures and biological effects of the resulting dispersion. Hence, before a final 756 conclusion can be made on the most appropriate sonication methods - especially from a 757 (eco)toxicity testing point of view - well designed studies are needed to investigate the influence of 758 sonication procedures and settings, such as frequency and time, on dispersibility as well as 
759 (eco)toxicity. This would include an examination of the cause of any sonication-dependent changes 760 to ENP properties linked to the observed biological effects.

761 The addition of dispersants is a somewhat controversial issue as it may either mask or enhance 762 the biological activity of the ENP (Cupi et al. 2015). A thorough evaluation of available dispersants 763 is needed to better understand their influence and mode of influence on ENP biological effects, 764 behavior during sonication, including formation of (toxic) degradation products, and during 765 biological exposure such as potential bio-modifications. If addition of dispersants cannot be 766 avoided, methods are needed to take into account modifications of ENP by addition of dispersants 767 when performing biological tests.

768 In the suggested step-wise approach to develop tailored stock dispersion (Figure 2) the 769 underlying principles were to minimize changes to the pristine ENP in order to reduce the risk of 770 testing artefacts and to obtain a stable dispersion. The actual quantitative (or qualitative) criteria for 771 characterizing a dispersion as 'stable' need to be defined on a case-by-case basis. The diagram is 772 flexible in the sense that other aims or quality criteria could be established based on specific 773 protocol requirements. For example criteria may be included with respect to 774 (mono/poly)dispersibility, particle size distributions, and acceptable physiochemical changes. It 775 could also be argued that, from a regulatory perspective, mono-dispersibility around a small average 776 peak size needs to be included as a criterion reflecting a worst-case situation with higher probability 777 of nano-specific effects. With this in mind the step-wise approach shown in Figure 2 is proposed as 778 a starting point for further discussions and developments on this topic.

\section{CONCLUSIONS}

780 This study provides an overview of current practice in selected dispersion protocols as well as 781 potential implications for mammalian and ecotoxicity testing. Based on an identification of critical 782 issues and parameters to be taken into account in protocol development for stock dispersion 
783 preparation, a step-wise approach for tailored dispersion protocols is presented describing the key 784 protocol parameters: particle concentration, pre-wetting, dispersion media, sonication and 785 dispersants. The developed approach provides an adaptable framework which may serve as a 786 starting point for further work towards developments of harmonized dispersion protocol for ENP. It 787 needs to be emphasized that appropriate controls needs to be included in all steps in the dispersion 788 procedure that are likely to entail modifications of the material properties or surface chemistry. 789 Through the analysis, leading to the suggested step-wise approach, a number of issues were 790 identified that require clarification and guidance development, of which the more critical issues 791 relate to the development of:

$792 \quad-\quad$ Measuring and reporting schemes for effective sonication energy input

$793 \quad-\quad$ Links between sonication procedures and biological effects

$794 \quad$ - Methods of taking into account modifications of ENP properties and effects when adding 795 dispersants to ENP suspensions.

796 A common approach to preparation of stock dispersion prior to toxicity testing may improve the 797 possibility of defining meaningful quality control and validity criteria and hence facilitate data 798 comparability, and ultimately enable future QSAR developments by providing more coherent 799 datasets. It is our intention that the proposed step-wise approach be used for development and 800 reporting of future development of protocols for both scientific, regulatory and standardization $801 \quad$ activities on ENP dispersion protocols.

802

803 Acknowledgements

804 The authors acknowledge the scientific and intellectual input to the ideas summarized in this paper 805 by the contributors to the work on harmonized dispersion protocols within the FP7 projects 806 MARINA (Managing Risks of Nanomaterials, European Commission, Grant Agreement Number 
807 263215), EnvNano (ERC Starting Grant, Grant Agreement Number 281579) and NANoREG (A

808 common European approach to the regulatory testing of Manufactured Nanomaterials; European

809 Commission, Grant Agreement Number 310584). The results in this paper primarily originates from

810 previous work and the results of the 'Workshop on harmonization of dispersion protocols' held as

811 part of the MARINA project at the European Commission Joint Research Centre, Ispra, Italy, 22-23

812 October 2012. In addition to the authors of this paper the participants at the workshop were: Julia

813 Catalán, Teresa Fernandes, Richard Handy, Alice Harling, Bryan Hellack, Kerstin Hund-Rinke,

814 José María Navas, and Janeck Scott-Fordsmand. In addition the authors would like to acknowledge

815 Frank von der Kammer and Craig Poland for their constructive feedback on the workshop

816 background report. 


\section{References}

819

820

821

822

823

824

825

826

827

828

829

830

831

832

833

834

835

836

837

838

839

840

841

842

843

844

845

846

847

848

849

850

851

Akaighe, N., Depner, S. W., Banerjee, S., Sharma, V. K., \& Sohn, M. (2012). The effects of monovalent and divalent cations on the stability of silver nanoparticles formed from direct reduction of silver ions by Suwannee River humic acid/natural organic matter. Sci Total Environ, 441:277-289.

Baalousha, M., Nur, Y., Römer, I., Tejamaya, M., \& Lead, J. R. (2013). Effect of monovalent and divalent cations, anions and fulvic acid on aggregation of citrate-coated silver nanoparticles. Sci Total Environ 454: 119-131.

Badawy, A. M. E., Luxton, T. P., Silva, R. G., Scheckel, K. G., Suidan, M. T., \& Tolaymat, T. M. (2010). Impact of environmental conditions ( $\mathrm{pH}$, ionic strength, and electrolyte type) on the surface charge and aggregation of silver nanoparticles suspensions. Environ Sci \& Techn, 44:1260-1266.

Baun, A., Hartmann, N. B., Grieger, K., \& Kusk, K. O. (2008). Ecotoxicity of engineered nanoparticles to aquatic invertebrates: A brief review and recommendations for future toxicity testing. Ecotoxicology, 17: 387-395.

Bihari, P., Vippola, M., Schultes, S., Praetner, M., Khandoga, A. G., Reichel, C. A., Coester, C., Tuomi,T., Rehberg M. \& Krombach, F. (2008). Optimized dispersion of nanoparticles for biological in vitro and in vivo studies. Part Fibre Toxicol 5:14.

Brown, B., \& Goodman, J. E. (1965). High-intensity Ultrasonics: Industrial Applications. Iliffe Books.

Brown, S. D., \& Brown, L. A. S. (2012). Ethanol (EtOH)-induced TGF- $\beta 1$ and reactive oxygen species production are necessary for EtOH-induced alveolar macrophage dysfunction and induction of alternative activation. Alcoholism: Clin Exp Res 36: 1952-1962.

Buffle, J., \& van Leeuwen, H. P. (1992). Environmental Particles. Lewis Publishers.

Byrne, H. J., Lynch, I., de Jong, W. H., Kreyling, W. G., Loft, S., Park, M. V. D. Z., Riediker, M. \& Warheit, D. (2010). Protocols for assessment of biological hazards of engineered nanomaterials. In NanoImpactNet Reports; The European Network on the Health and Environmental Impact of Nanomaterials. Available online: http://www.nanoimpactnet.eu/index.php?page=reports [Accessed 14/7 2015].

Caneba, G. T., Dutta, C., Agrawal, V., \& Rao, M. (2010). Novel ultrasonic dispersion of carbon nanotubes. JMineral Mater Character Eng 9:165.

Capelo-Martínez, J. L. (Ed.). (2008). Ultrasound in Chemistry: Analytical Applications. John Wiley \& Sons.

Caro, A. A., \& Cederbaum, A. I. (2004). Oxidative stress, toxicology, and pharmacology of CYP2E1*. Annu. Rev. Pharmacol. Toxicol., 44:27-42. 
852 Chen, K. L., \& Elimelech, M. (2007). Influence of humic acid on the aggregation kinetics of

853

854

855

856

857

858

859

860

861

862

863

864

865

866

867

868

869

870

871

872

873

874

875

876

877

878

879

880

881

882

883

884

885

886

fullerene (C 60) nanoparticles in monovalent and divalent electrolyte solutions. J Colloid Interface Sci 309:126-134.

Choi, J., Kim, H., Kim, P., Jo, E., Kim, H. M., Lee, M. Y., Jin, S.M. \& Park, K. (2015). Toxicity of Zinc Oxide Nanoparticles in Rats Treated by Two Different Routes: Single Intravenous Injection and Single Oral Administration. J Toxicol Environ Health A 78: 226-243.

Cronholm, P., Midander, K., Karlsson, H. L., Elihn, K., Wallinder, I. O., \& Möller, L. (2011). Effect of sonication and serum proteins on copper release from copper nanoparticles and the toxicity towards lung epithelial cells. Nanotoxicology, 5: 269-281.

Cupi, D. (2015). Engineered Nanoparticle (Eco)Toxicity: Towards Standardized Procedures for Hazard Identification. Ph.D. thesis, Technical University of Denmark, DTU Environment, Kgs. Lyngby.

Cupi, D., Hartmann, N. B., \& Baun, A. (2015). The influence of natural organic matter and aging on suspension stability in guideline toxicity testing of silver, zinc oxide, and titanium dioxide nanoparticles with Daphnia magna. Environ Toxicol Chem 34: 497-506.

Domingos, R. F., Rafiei, Z., Monteiro, C. E., Khan, M. A., \& Wilkinson, K. J. (2013).

Agglomeration and dissolution of zinc oxide nanoparticles: Role of $\mathrm{pH}$, ionic strength and fulvic acid. Environ Chem 10: 306-312.

Domingos, R. F., Tufenkji, N., \& Wilkinson, K. J. (2009). Aggregation of titanium dioxide nanoparticles: Role of a fulvic acid. Environ Sci Technol 43: 1282-1286.

Edri, E., \& Regev, O. (2008). pH effects on BSA-dispersed carbon nanotubes studied by spectroscopy-enhanced composition evaluation techniques. Anal Chem 80: 4049-4054.

European Commission (EC). (2006). REACH: Regulation (EC) No 1907/2006 of the European Parliament and of the Council of 18 December 2006 concerning the Registration, Evaluation, Authorisation and Restriction of Chemicals (REACH), establishing a European Chemicals Agency, amending Directive 1999/45/EC and repealing Council Regulation (EEC) No 793/93 and Commission Regulation (EC) No 1488/94 as well as Council Directive 76/769/EEC and Commission Directives 91/155/EEC, 93/67/EEC, 93/105/EC and 2000/21/EC. Off J Eur Union. L 396, 30.12.2006, pp. 1-849

European Commission (EC). (2008). CLP: Regulation (EC) No 1272/2008 of the European Parliament and of the Council of 16 December 2008 on classification, labelling and packaging of substances and mixtures, amending and repealing Directives 67/548/EEC and 1999/45/EC, and amending Regulation (EC) No 1907/2006. OJ L 353, 2008, pp. 1-1355.

Farré, M., Gajda-Schrantz, K., Kantiani, L., \& Barceló, D. (2009). Ecotoxicity and analysis of nanomaterials in the aquatic environment. Anal Bioanal Chem 393: 81-95. 
887 Feiler, A., Jenkins, P., \& Ralston, J. (2000). Metal oxide surfaces separated by aqueous solutions of 888 linear polyphosphates: DLVO and non-DLVO interaction forces.

889 Phys Chem Chem Phys 2: 5678-5683.

890 Franklin, N. M., Rogers, N. J., Apte, S. C., Batley, G. E., Gadd, G. E., \& Casey, P. S. (2007).

891 Comparative toxicity of nanoparticulate $\mathrm{ZnO}$, bulk $\mathrm{ZnO}$, and $\mathrm{ZnCl} 2$ to a freshwater microalga

892 (Pseudokirchneriella subcapitata): the importance of particle solubility. Environ Sci Technol 41:

893 8484-8490.

894 Gao, J., Llaneza, V., Youn, S., Silvera-Batista, C. A., Ziegler, K. J., \& Bonzongo, J. C. J. (2012b). 895 Aqueous suspension methods of carbon-based nanomaterials and biological effects on model 896 aquatic organisms. Environ Toxicol Chem 31: 210-214.

897 Gao, J., Powers, K., Wang, Y., Zhou, H., Roberts, S. M., Moudgil, B. M., Koopman, B \& Barber, 898 D. S. (2012a). Influence of Suwannee River humic acid on particle properties and toxicity of silver 899 nanoparticles. Chemosphere, 89: 96-101.

900 Godymchuk, A., Arzamastseva, E., Kuznetsov, D., \& Milyaeva, S. (2011). Dispersion of ZrO2 and 901 Y2O3 nanopowders in physiological suspensions. In Journal of Physics: Conference Series (Vol. 902 304, No. 1, p. 012043). IOP Publishing.

903 Guiot, C., \& Spalla, O. (2012). Stabilization of TiO2 nanoparticles in complex medium through a 904 pH adjustment protocol. Environ Sci Technol 47: 1057-1064.

905 Handy, R.D., Henry, T.B., Scown, T.M., Johnston, B.D., \& Tyler, C.R. (2008a). Manufactured

906 nanoparticles: Their uptake and effects on fish-a mechanistic analysis. Ecotoxicology 17:396-409

907 Handy, R. D., Owen, R., \& Valsami-Jones, E. (2008b). The ecotoxicology of nanoparticles and 908 nanomaterials: Current status, knowledge gaps, challenges, and future needs. Ecotoxicology, 17: $909 \quad 315-325$.

910 Handy, R. D., Cornelis, G., Fernandes, T., Tsyusko, O., Decho, A., Sabo-Attwood, T., Metcalfe, C., 911 Steevens, J. A., Klaine, S.J. \& Koelmans, A. A. (2012a). Ecotoxicity test methods for engineered 912 nanomaterials: Practical experiences and recommendations from the bench. Environ Toxicol 913 Chem 31: 15-31.

914 Handy, R. D., van den Brink, N., Chappell, M., Mühling, M., Behra, R., Dušinská, M., Simpson, P., 915 Ahtiainen, J., Jha, A. N., Seiter, J., Bednar, A., Kennedy, A., Fernandes, T. F. and Riediker, M. 916 (2012b) Practical considerations for conducting ecotoxicity test methods with manufactured 917 nanomaterials: What have we learnt so far? Ecotoxicology, 21: 933-972

918 Hartmann, N. B. (2011). Ecotoxicity of engineered nanoparticles to freshwater organisms. PhD 919 thesis. Kgs. Lyngby, Denmark: Technical University of Denmark (DTU). 
920 Hartmann, N. B., Engelbrekt, C., Zhang, J., Ulstrup, J., Kusk, K. O., \& Baun, A. (2012). The

921 challenges of testing metal and metal oxide nanoparticles in algal bioassays: Titanium dioxide and

922 gold nanoparticles as case studies. Nanotoxicology, 7: 1082-1094.

923 Henry, T. B., Menn, F. M., Fleming, J. T., Wilgus, J., Compton, R. N., \& Sayler, G. S. (2007).

924 Attributing effects of aqueous C60 nano-aggregates to tetrahydrofuran decomposition products in

925 larval zebrafish by assessment of gene expression. Environ Health Persp 115:1059-1065.

926 Horst, A. M., Ji, Z., \& Holden, P. A. (2012). Nanoparticle dispersion in environmentally relevant

927 culture media: a TiO2 case study and considerations for a general approach.

928 J Nanopart Res 14: 1-14.

929 Hotze, E. M., Phenrat, T., \& Lowry, G. V. (2010). Nanoparticle aggregation: Challenges to

930 understanding transport and reactivity in the environment. J Environ Qual 39: 1909-1924.

931 IMLAB. 2013. HIELSCHER: Sonificateur, homogénéiseur à ultrasons, sonotrode URL :

932 http://www.imlab.com/fr/hielscher.htm [Accessed March 31 2015].

933 International Organization for Standardization (ISO). (2008). ISO/TS 27687:2008:

934 Nanotechnologies - Terminology and definitions for nano-objects - Nanoparticle, nanofibre and

935 nanoplate.

936 Jacobsen, N. R., Moller, P., Jensen, K. A., Vogel, U., Ladefoged, O., Loft, S., \& Wallin, H. (2009).

937 Lung inflammation and genotoxicity following pulmonary exposure to nanoparticles in ApoE-/-

938 mice. Part Fibre Toxicol, 6: 2.

939 Jacobsen, N. R., Pojano, G., Wallin, H. \& Jensen, K. A. (2010). Nanomaterial dispersion protocol

940 for toxicological studies in ENPRA. Internal ENPRA Project Report. Copenhagen, Denmark: The

941 National Research Centre for the Working Environment.

942 Jensen K. A., Kembouche, Y., Christiansen, E., Jacobsen, N. R., Wallin, H., Guiot, C., Spalla, O. \&

943 Witschger, O. 2011a. Final protocol for producing suitable manufactured nanomaterial exposure

944 media. Web-Report. The generic NANOGENOTOX dispersion protocol - Standard Operation

945 Procedure (SOP). October, 2011.

946 Jensen K. A., Kembouche, Y., Christiansen, E., Jacobsen, N. R., Wallin, H., Guiot, C., Spalla, O. \& 947 Witschger, O. 2011 b.Final protocol for producing suitable manufactured nanomaterial exposure

948 media - Report The generic NANOGENOTOX dispersion protocol - Standard Operation

949 Procedure (SOP) and background documentation. July, 2011.

950 Jensen K. A., Kembouche, Y., Christiansen, E., N. R., Wallin, H., Guiot, C., Spalla, O., Witschger, 951 O. (2011c). Deliverable 3: Final protocol for producing suitable MN exposure media. Edited by 952 Jensen K.A. and Thieret N. June 2011.

953 Jensen, K. A., Pojana G. \& Bilanicora, D. (2014). Chapter 4: Characterization of manufactured 954 nanomaterials, dispersion and exposure characterization for toxicological testing. In 
955 Nanotoxicology: Progress Towards Nanomedicine, Eds. N.A. Monteiro-Riviere and C. L. Tran.

956 CRC Press, Taylor and Francis Group, Boca Raton, Florida, USA. pp. 45-73.

957 Ji, Z., Jin, X., George, S., Xia, T., Meng, H., Wang, X., Suarez, E., Zhang, H., Hoek, E. M. V., 958 Godwin, H., Nel, A. E. \& Zink, J. I. (2010). Dispersion and stability optimization of TiO2 959 nanoparticles in cell culture media. Environ Sci Technol 44: 7309-7314.

960 Jiang, J., Oberdörster, G., \& Biswas, P. (2009). Characterization of size, surface charge, and 961 agglomeration state of nanoparticle dispersions for toxicological studies. J Nanopart Res 11: 77-89.

962 Jo, H.J., Choi, J.W., Lee, S.H., \& Hong, S.W. 2012. Acute toxicity of Ag and CuO nanoparticle 963 suspensions against Daphnia magna: The importance of their dissolved fraction varying with 964 preparation methods. J Hazard Mater 227:301-308.

965 Kim, J. S., Song, K. S., Lee, J. H., \& Yu, I. J. (2011). Evaluation of biocompatible dispersants for 966 carbon nanotube toxicity tests. ArchToxicol 85: 1499-1508.

967 Kim, J. Y., Kim, K. T., Lee, B. G., Lim, B. J., \& Kim, S. D. (2013). Developmental toxicity of 968 Japanese medaka embryos by silver nanoparticles and released ions in the presence of humic acid. 969 Ecotoxicol Environ Saf 92: 57-63.

970 Kördel, W., Dassenakis, M., Lintelmann, J., \& Padberg, S. (1997). The importance of natural 971 organic material for environmental processes in waters and soils (Technical Report).

972 Pure Appl Chem 69: 1571-1600.

973 Kosmulski, M. (2009). pH-dependent surface charging and points of zero charge. IV. Update and 974 new approach. J Colloid Interface Sci337: 439-448.

975 Kühnel, D., \& Nickel, C. (2014). The OECD expert meeting on ecotoxicology and environmental 976 fate- towards the development of improved OECD guidelines for the testing of nanomaterials. 977 Sci Total Environ472: 347-353.

978 Laban, G., Nies, L. F., Turco, R. F., Bickham, J. W., \& Sepúlveda, M. S. (2010). The effects of 979 silver nanoparticles on fathead minnow (Pimephales promelas) embryos. Ecotoxicology, 19: 185980195.

981 Lee, Y. G., Jeong, J., Raftis, J., \& Cho, W. S. (2015). Determination of Adsorption Affinity of 982 Nanoparticles for Interleukin-8 Secreted From A549 Cells by In Vitro Cell-Free and Cell-Based 983 Assays. J Toxicol Environ Health A 78:185-195.

984 Li, M., Lin, D., \& Zhu, L. (2013). Effects of water chemistry on the dissolution of ZnO 985 nanoparticles and their toxicity to Escherichia coli. Environ Pollut 173 : 97-102.

986 Li, S., Li, H., Wang, X., Song, Y., Liu, Y., Jiang, L., \& Zhu, D. (2002). Super-hydrophobicity of 987 large-area honeycomb-like aligned carbon nanotubes. J Phys Chem B, 106: 9274-9276. 
988 Magdolenova, Z., Lorenzo, Y., Collins, A., \& Dusinska, M. (2012). Can standard genotoxicity tests 989 be applied to nanoparticles?. Journal of Toxicology and Environmental Health, Part A, 75(13-15), $990 \quad 800-806$.

991 Manier, N., Garaud, M., Delalain, P., Aguerre-Chariol, O., \& Pandard, P. (2011, July). Behaviour of 992 ceria nanoparticles in standardized test media-influence on the results of ecotoxicological tests. In 993 Journal of Physics: Conference Series (Vol. 304, No. 1, p. 012058). IOP Publishing.

994 McCarthy, J. F., \& McKay, L. D. (2004). Colloid transport in the subsurface.

995 Vadose Zone J 3: 326-337.

996 Mejia, J., Valembois, V., Piret, J. P., Tichelaar, F., van Huis, M., Masereel, B., Toussaint, O., 997 Delhalle, J., Mekhalif, Z. \& Lucas, S. (2012). Are stirring and sonication pre-dispersion methods 998 equivalent for in vitro toxicology evaluation of SiC and TiC?. J Nanopart Res 14: 1-18.

999 Menard, A., Drobne, D., \& Jemec, A. (2011). Ecotoxicity of nanosized TiO 2. Review of in vivo 1000 data. Environ Pollut 159: 677-684.

1001 Morison, K. R., \& Hutchinson, C. A. (2009). Limitations of the Weissler reaction as a model 1002 reaction for measuring the efficiency of hydrodynamic cavitation. Ultrasonics Sonochem 16: 1761003183.

1004 NANOMMUNE 2011. Chapter 2.4.1. SOP NANOMMUNE 3.07 v2 Dispersion of nanomaterials 1005 for in vitroExperiments. In: Quality Handbook Standard Procedures for Nanoparticle Testing. 1006 Krug, H. F. (Ed.). (2011). Nanommune.

1007 Oberdörster, E. (2004). Manufactured nanomaterials (fullerenes, C60) induce oxidative stress in the 1008 brain of juvenile largemouth bass. Environ Health Persp, 112: 1058-1062.

1009 OECD. (1981). Decision of the Council concerning the Mutual Acceptance of Data in the 1010 Assessment of Chemicals. 12 May 1981 - C(81)30/FINAL. Amended on 26 November 1997 1011 C(97)186/FINAL. Organization for Economic Cooperation and Development, Paris.

1012 OECD. (2012). Guidance on Sample Preparation and Dosimetry for the Safety Testing of 1013 Manufactured Nanomaterials. Series on the Safety of Manufactured Nanomaterials No. 36. 1014 Organization for Economic Cooperation and Development, Paris.

1015 OECD. (2013). OECD Guidelines for the Testing of Chemicals. Organization for Economic 1016 Cooperation and Development, Paris. URL:

1017 http://www.oecd.org/env/ehs/testing/oecdguidelinesforthetestingofchemicals.htm [Accessed 31/3 1018 2015].

1019 Ottofuelling, S., Von Der Kammer, F., \& Hofmann, T. (2011). Commercial titanium dioxide 1020 nanoparticles in both natural and synthetic water: Comprehensive multidimensional testing and 1021 prediction of aggregation behavior. Environ Sci Technol 45: 10045-10052. 
1022 PROSPEcT 2010. Protocol for Nanoparticle Dispersion. 18 May 2010. URL:

1023

1024 http://www.nanotechia.org/sites/default/files/files/PROSPECT_Dispersion_Protocol.pdf [Accessed $31 / 32015]$.

1025 Riesz, P., \& Kondo, T. (1992). Free radical formation induced by ultrasound and its biological 1026 implications. Free Radic Biol Med 13: 247-270.

1027 Römer, I., Gavin, A. J., White, T. A., Merrifield, R. C., Chipman, J. K., Viant, M. R., \& Lead, J. R. 1028 1029 (2013). The critical importance of defined media conditions in Daphnia magna nanotoxicity studies. Toxicol Lett 223: 103-108.

1030 Roursgaard, M., Poulsen, S. S., Poulsen, L. K., Hammer, M., Jensen, K. A., Utsunomiya, S., Ewing, 1031 R. C., Balic-Zunic, T., Nielsen, G. D. \& Larsen, S. T. (2010). Time-response relationship of nano 1032 and micro particle induced lung inflammation. Quartz as reference compound. Human Exp Toxicol. 1033 29: 915-933.

1034 Ryan, J. (2004). Endotoxins and cell culture. Corning Life Sci Tech Bull 1-8.

1035 Salager, J. L. (1994). Interfacial phenomena in dispersed systems. FIRP Booklet, 120.

1036 Schneider, T., \& Jensen, K. A. (2009). Relevance of aerosol dynamics and dustiness for personal 1037 exposure to manufactured nanoparticles. J Nanoparticle Research, 11: 1637-1650.

1038 Seitz, F., Bundschuh, M., Rosenfeldt, R. R., \& Schulz, R. (2013). Nanoparticle toxicity in Daphnia 1039 magna reproduction studies: The importance of test design. Aquat Toxicol 126: 163-168.

1040 Sillanpää, M. (2015). Chapter 1 - General Introduction, In Sillanpää, M. (ed), Natural Organic 1041 Matter in Water. Characterization and Treatment Methods, Butterworth-Heinemann, p. 1-15.

1042 Skjolding, L.M., Winther-Nielsen, M. \& Baun, A. (2014). Trophic transfer of differently 1043 functionalized zinc oxide nanoparticles from crustaceans (Daphnia magna) to zebrafish (Danio 1044 rerio). Aquatic Toxicology, 157:101-108.

1045 Snyder-Talkington, B. N., Qian, Y., Castranova, V., \& Guo, N. L. (2012). New perspectives for in 1046 vitro risk assessment of multiwalled carbon nanotubes: application of coculture and bioinformatics. 1047 Journal of Toxicology and Environmental Health, Part B, 15:468-492.

1048 Tantra, R., Schulze, P., \& Quincey, P. (2010). Effect of nanoparticle concentration on zeta-potential 1049 measurement results and reproducibility. Particuology, 8: 279-285.

1050 Tantra, R., Sikora, A., Hartmann, N. B., Sintes, J. R., \& Robinson, K. N. (2014). Comparison of the 1051 effects of different protocols on the particle size distribution of TiO 2 dispersions. Particuology $1052 \quad 19: 35-44$.

1053 Taurozzi, J. S., Hackley, V. A., \& Wiesner, M. R. (2011). Ultrasonic dispersion of nanoparticles for 1054 environmental, health and safety assessment-issues and recommendations. Nanotoxicology, 5: 1055 711-729. 
1056 Taurozzi, J. S., Hackley, V. A., Weisner, M. R. (2012a). NIST Special Publication 1200-1.

1057 Reporting Guidelines for the Preparation of Aqueous Nanoparticle Dispersions from Dry Materials.

1058 NIST xSpecial Publication. U.S. Department of Commerce / National Institute of Standards and

1059 Technology.

1060 Taurozzi, J.S., Hackley, V.A., Weisner, M.R. (2012b). NIST Special Publication 1200-2.

1061 Preparation of Nanoparticle Dispersions from Powdered Material Using Ultrasonic Disruption.

1062 NIST Special Publication. U.S. Department of Commerce / National Institute of Standards and

1063 Technology.

1064 Taurozzi, J. S., Hackley, V. A., Weisner, M. R. (2012c). NIST Special Publication 1200-3.

1065 Preparation of a Nanoscale TiO2 Aqueous Dispersion for Toxicological or Environmental Testing.

1066 NIST Special Publication. Version 1.2 ed.: U.S. Department of Commerce / National Institute of

1067 Standards and Technology.

1068 Taurozzi, J. S., Hackley, V. A., Weisner, M. R. (2012d). NIST Special Publication 1200-4.

1069 Preparation of Nanoscale TiO2 Dispersions in Biological Test Media for Toxicological Assessment.

1070 NIST Special Publication. Version 1.1 ed.: U.S. Department of Commerce / National Institute of

1071 Standards and Technology.

1072 Taurozzi, J. S., Hackley, V. A., Weisner, M. R. (2013). NIST Special Publication 1200-5r1.

1073 Preparation of Nanoscale TiO2 Dispersions in an Environmental Matrix for Eco-Toxicological

1074 Assessment. NIST Special Publication. Version 1.2 ed.: U.S. Department of Commerce / National

1075 Institute of Standards and Technology.

1076 Thio, B. J. R., Zhou, D., \& Keller, A. A. (2011). Influence of natural organic matter on the

1077 aggregation and deposition of titanium dioxide nanoparticles. J Hazard Mater 189: 556-563.

1078 Thomas, C. R., George, S., Horst, A. M., Ji, Z., Miller, R. J., Peralta-Videa, J. R., Xia, T., Pokhrel, 1079 S., Mädler, L., Gardea-Torresdey, J.L., Holden, P.A., Keller, A.A., Lenihan, H.S., Nel, A.E., \& 1080 Zink, J. I. (2011). Nanomaterials in the environment: from materials to high-throughput screening 1081 to organisms. ACS Nano, 5: 13-20.

1082 Tiller, C. L., \& O'Melia, C. R. (1993). Natural organic matter and colloidal stability: Models and 1083 measurements. Colloids and Surfaces A: Physicochem Eng Aspects, 73: 89-102.

1084 Truong, L., Saili, K. S., Miller, J. M., Hutchison, J. E., \& Tanguay, R. L. (2012). Persistent adult 1085 zebrafish behavioral deficits results from acute embryonic exposure to gold nanoparticles. Comp 1086 Biochem Physiol Part C: Toxicol Pharmacol 155: 269-274.

1087 von der Kammer, F., Ottofuelling, S., \& Hofmann, T. (2010). Assessment of the physico-chemical 1088 behavior of titanium dioxide nanoparticles in aquatic environments using multi-dimensional 1089 parameter testing. Environ Pollut 158: 3472-3481. 
1090 Wang, L., Castranova, V., Mishra, A., Chen, B., Mercer, R. R., Schwegler-Berry, D., \&

1091 Rojanasakul, Y. (2010a). Dispersion of single-walled carbon nanotubes by a natural lung surfactant

1092 for pulmonary in vitro and in vivo toxicity studies. Part Fibre tToxicol 7: 31.

1093 Wang, L., Mercer, R. R., Rojanasakul, Y., Qiu, A., Lu, Y., Scabilloni, J. F., Wu, N. \& Castranova, 1094 V. (2010b). Direct fibrogenic effects of dispersed single-walled carbon nanotubes on human lung

1095 fibroblasts. Journal of Toxicology and Environmental Health, Part A, 73(5-6), 410-422.

1096 Wang, R., Hughes, T., Beck, S., Vakil, S., Li, S., Pantano, P., \& Draper, R. K. (2012). Generation

1097 of toxic degradation products by sonication of Pluronic $\AA$ dispersants: implications for nanotoxicity 1098 testing. Nanotoxicology, 7: 1272-1281.

1099 Weyman, G. S., Rufli, H., Weltje, L., Salinas, E. R., \& Hamitou, M. (2012). Aquatic toxicity tests 1100 with substances that are poorly soluble in water and consequences for environmental risk 1101 assessment. Environ Toxicol Chem 31: 1662-1669.

1102 Wilkinson, K. J., Negre, J. C., \& Buffle, J. (1997). Coagulation of colloidal material in surface 1103 waters: the role of natural organic matter. J Contaminant Hydrol 26: 229-243.

1104 Yang, K., Lin, D., \& Xing, B. (2009). Interactions of humic acid with nanosized inorganic oxides. 1105 Langmuir, 25: 3571-3576.

1106 Zhang, Y., Chen, Y., Westerhoff, P., \& Crittenden, J. (2009). Impact of natural organic matter and 1107 divalent cations on the stability of aqueous nanoparticles. Water Res 43: 4249-4257.

1108 Zhou, D., \& Keller, A. A. (2010). Role of morphology in the aggregation kinetics of ZnO 1109 nanoparticles. Water Res 44: 2948-2956.

1110 Zhu, M., Wang, H., Keller, A. A., Wang, T., \& Li, F. (2014). The effect of humic acid on the 1111 aggregation of titanium dioxide nanoparticles under different $\mathrm{pH}$ and ionic strengths. Science of the 1112 Total Environment, 487, 375-380.

1113 Zhu, S., Oberdörster, E., \& Haasch, M. L. (2006). Toxicity of an engineered nanoparticle (fullerene, $1114 \mathrm{C} 60)$ in two aquatic species, Daphnia and fathead minnow.

1115 Mar Environ Res 62:S5-S9. 
Table 1. Overview of some existing protocols for dispersing ENPs in aquatic media.

\begin{tabular}{|c|c|c|c|c|c|}
\hline Project / organisation & CEINT / NIST (1200-3) & NANOGENOTOX & NANOIMMUNE & PROSPEcT & ENPRA \\
\hline Year of publication & 2012 & 2011 & 2011 & 2010 & 2010 \\
\hline Testing regime & $\begin{array}{l}\text { Toxicity (in vitro) and } \\
\text { ecotoxicity (acute) } \\
\text { testing }\end{array}$ & $\begin{array}{l}\text { Toxicity testing (in vivo } \\
\text { and in vitro) }\end{array}$ & $\begin{array}{l}\text { Immunotoxicity testing } \\
\text { (in vivo and in vitro) }\end{array}$ & $\begin{array}{l}\text { Ecotoxicity (and toxicity) } \\
\text { testing }\end{array}$ & $\begin{array}{l}\text { Toxicity testing (in vivo } \\
\text { and in vitro) }\end{array}$ \\
\hline $\begin{array}{l}\text { ENP(s) used in } \\
\text { protocol development }\end{array}$ & $\mathrm{TiO}_{2}$ & $\mathrm{SiO}_{2}, \mathrm{TiO}_{2}, \mathrm{MWCNT}$ & $\begin{array}{l}\text { e.g. } \mathrm{TiO}_{2}, \mathrm{ZnO}, \mathrm{SiO}_{2} \text {, } \\
\text { CNTs and various } \mathrm{Fe} \\
\text { ENPs }\end{array}$ & $\mathrm{CeO}_{2}, \mathrm{ZnO}$ & $\begin{array}{l}\mathrm{TiO}_{2}, \mathrm{ZnO} \text { uncoated, } \\
\mathrm{ZnO} \text { coated, Ag, } \\
\text { MWCNT }\end{array}$ \\
\hline $\begin{array}{l}\text { Stock concentration } \\
(\mathrm{mg} / \mathrm{ml})\end{array}$ & $0.5-20 \mathrm{mg} / \mathrm{ml}$ & $2.56 \mathrm{mg} / \mathrm{ml}$ & $\begin{array}{l}1 \mathrm{mg} / \mathrm{ml} \text { (general), } 0.25 \\
\mathrm{mg} / \mathrm{ml} \text { (CNTs) }\end{array}$ & $\begin{array}{l}1 \mathrm{mg} / \mathrm{ml} \text { diluted to } 0.015 \\
\mathrm{mg} / \mathrm{ml}\left(\mathrm{CeO}_{2}\right) \\
2.56 \mathrm{mg} / \mathrm{ml}(\text { coated } \mathrm{ZnO})\end{array}$ & $2.56 \mathrm{mg} / \mathrm{ml}$ \\
\hline $\begin{array}{l}\text { Volume of dispersion } \\
\text { medium }\end{array}$ & $50 \mathrm{~mL}$ & $6 \mathrm{~mL}$ & - & $\begin{array}{l}\text { Approximately } 15 \mathrm{~mL}\left(\mathrm{CeO}_{2}\right) \\
\text { 4-6 } \mathrm{mL} \text { (coated } \mathrm{ZnO})\end{array}$ & $6 \mathrm{~mL}$ \\
\hline Pre-wetting & No & $\begin{array}{l}\text { Yes, generically with } \\
0.5 \text { vol\% ethanol for all } \\
\text { ENPs }\end{array}$ & No & $\begin{array}{l}\text { Yes, with DI water for } \mathrm{CeO}_{2} \text {, } \\
\text { and with } 0.5 \text { vol } \% \text { ethanol for } \\
\text { coated } \mathrm{ZnO}\end{array}$ & $\begin{array}{l}\text { Yes, with } 0.5 \mathrm{vol} \% \\
\text { ethanol for both coated } \\
\text { and uncoated } \mathrm{ZnO}\end{array}$ \\
\hline Dispersion media & $\begin{array}{l}\text { Type } 1 \text { biological grade } \\
\text { (sterile) DI water }\end{array}$ & $\begin{array}{l}\text { Purest water available } \\
\text { (e.g. Nanopure and } \\
\text { MilliQ water) }\end{array}$ & Ultrapure water & $\begin{array}{l}\text { DI water }\left(\mathrm{CeO}_{2}\right), \\
\text { Highest standard DI water } \\
\text { available and filtration } \\
\text { through a filter } \leq 0.45 \mu \mathrm{m} \\
\text { (coated } \mathrm{ZnO} \text { ) }\end{array}$ & $\begin{array}{l}0.45 \mu \mathrm{m} \text { filtered DI } \\
\text { water or higher quality }\end{array}$ \\
\hline
\end{tabular}




\begin{tabular}{|c|c|c|c|c|c|}
\hline Resistivity & $18 \mathrm{M} \Omega \cdot \mathrm{cm}$ & $\begin{array}{l}\text { Up to } 18.2 \mathrm{M} \Omega \cdot \mathrm{cm} \text {, } \\
\text { (Nanopure Diamond } \\
\text { UV Water ), } 18.2 \\
\mathrm{M} \Omega \cdot \mathrm{cm} \text { (MilliQ water) }\end{array}$ & - & $\sim 18 \mathrm{M} \Omega \cdot \mathrm{cm}$ & - \\
\hline Pyrogens & $\begin{array}{l}\text { Absence of endotoxin } \\
\text { contamination }\end{array}$ & $\begin{array}{l}<0.001 \mathrm{EU} / \mathrm{ml} \\
\text { (Nanopure Diamond } \\
\text { UV Water), }<0.02 \\
\text { Endotoxin Units/ml } \\
\text { (MilliQ water) }\end{array}$ & $\begin{array}{l}\text { Lipopolysaccharides }< \\
0.25 \mathrm{ng} / \mathrm{ml}\end{array}$ & - & - \\
\hline Sonication & Yes & Yes & Yes & Yes & Yes \\
\hline Means of sonication & Probe sonication & Probe sonication & $\begin{array}{l}\text { Probe sonication }\left(\mathrm{SiO}_{2}\right. \\
\text { and metal oxides). } \\
\text { Ultrasonic bath for } \\
\text { CNTs }\end{array}$ & Probe sonication & Probe sonication \\
\hline Sonicator settings & $\begin{array}{l}50 \mathrm{~W} \text {, pulsed operation } \\
\text { mode }(80 \% \text { on } / 20 \% \\
\text { off })\end{array}$ & $\begin{array}{l}400 \mathrm{~W} \text { at preferably } \\
10 \% \text { amplitude }\end{array}$ & - & $\begin{array}{l}130 \mathrm{~W} \text { at } 90 \% \text { amplitude } \\
\left(\mathrm{CeO}_{2}\right) \\
400 \mathrm{~W}(\text { coated } \mathrm{ZnO})\end{array}$ & $\begin{array}{l}400 \mathrm{~W} \text { at } 10 \% \\
\text { amplitude }\end{array}$ \\
\hline Time & $15 \mathrm{~min}$ & $\begin{array}{l}16 \text { min ( } 12 \text { min for } \\
\text { instruments that cannot } \\
\text { go below } 20 \% \\
\text { amplitude) }\end{array}$ & $\begin{array}{l}3 \times 20 \mathrm{sec}(5 \mathrm{sec} \text { break }) \\
\left(\mathrm{SiO}_{2}\right), 2 \mathrm{~min}(\mathrm{metal} \\
\text { oxides }), 2 \times 10 \mathrm{~min} \mathrm{w} / \\
\text { vortex }(\mathrm{CNTs})\end{array}$ & $\begin{array}{l}20 \mathrm{sec}\left(\mathrm{CeO}_{2}\right), 16 \mathrm{~min} \text { (coated } \\
\mathrm{ZnO})\end{array}$ & $16 \mathrm{~min}$ \\
\hline Cooling & On ice water bath & On ice water bath & $\begin{array}{l}\text { On ice }\left(\mathrm{SiO}_{2} \text { and metal }\right. \\
\text { oxides) }\end{array}$ & $\begin{array}{l}\text { On ice water bath (optional for } \\
\mathrm{CeO}_{2} \text { ) }\end{array}$ & On ice water bath \\
\hline $\begin{array}{l}\text { Dispersant in stock } \\
\text { dispersion }\end{array}$ & No & $\begin{array}{l}0.05 \% \mathrm{w} / \mathrm{v} \text { Bovine } \\
\text { Serum. It is } \\
\text { recommended that the }\end{array}$ & $\begin{array}{l}160 \mathrm{ppm} \text { Pluronic F126 } \\
\text { (CNTs), not added for }\end{array}$ & $\begin{array}{l}\text { For toxicity testing: } 2 \text { vol } \% \\
\text { mouse serum (in vivo) or } 2 \%\end{array}$ & $\begin{array}{l}2 \text { vol\% serum (e.g. } \\
\text { bovine or mouse) }\end{array}$ \\
\hline
\end{tabular}




\begin{tabular}{|c|c|c|c|c|c|}
\hline & & $\begin{array}{l}\text { albumin type is adjusted } \\
\text { according to the species } \\
\text { tested }\end{array}$ & other materials. & serum of choice (in vitro) & \\
\hline $\begin{array}{l}\text { Subsequent addition } \\
\text { of stabilising / } \\
\text { dispersing agents }\end{array}$ & $\begin{array}{l}\text { Bovine Serum Albumin } \\
\text { (Toxicological testing, } \\
\text { NIST 1200-4) or Humic } \\
\text { Acid (Environmental } \\
\text { Testing, NIST 1200- } \\
\text { 5r1). }\end{array}$ & - & - & - & - \\
\hline $\begin{array}{l}\text { Recommended } \\
\text { maximum time } \\
\text { between stock } \\
\text { preparation to use in } \\
\text { test }\end{array}$ & $\begin{array}{l}48 \text { hours (stability } \\
\text { validated) }\end{array}$ & $\begin{array}{l}1 \text { hour (stability } \\
\text { validated). Can be re- } \\
\text { dispersed by shaking }\end{array}$ & $\begin{array}{l}\text { Max. } 1 \text { day. If the time } \\
\text { between stock } \\
\text { preparation and use in } \\
\text { test exceeds } 30 \mathrm{~min} \text {. then } \\
\text { the stock should be } \\
\text { sonicated prior to } \\
\text { dilution in test media }\end{array}$ & $\begin{array}{l}\text { Stable for } 1 \text { hour but } \\
\text { immediate use is } \\
\text { recommended }\end{array}$ & $\begin{array}{l}1 \text { hour (stability } \\
\text { validated). Can be re- } \\
\text { dispersed by shaking }\end{array}$ \\
\hline Quality assurance & LDS/DLS/XDC and $\mathrm{pH}$ & $\begin{array}{l}\text { DLS and qualitative } \\
\text { support from optical } \\
\text { microscopy }\end{array}$ & $\begin{array}{l}\text { Analytical } \\
\text { ultracentrifugation/laser } \\
\text { diffraction/DLS, zeta } \\
\text { potential, and } \\
\text { measurements of } \\
\text { dissolved ions }\end{array}$ & DLS & $\begin{array}{l}\text { DLS and qualitative } \\
\text { support from optical } \\
\text { microscopy }\end{array}$ \\
\hline
\end{tabular}


Table 12. Advantages and disadvantages of common sonicator types.

\begin{tabular}{|l|l|l|}
\hline Sonicator type & Relative Advantages & Relative Disadvantages \\
\hline Bath (indirect) & Low risk of contamination & Low rate energy output \\
& Larger volumes can be handled & Poor control of delivered energy \\
\hline $\begin{array}{l}\text { Probe (horn) } \\
\text { sonication (direct) }\end{array}$ & $\begin{array}{l}\text { High rate of energy output } \\
\text { Good control of delivered energy } \\
\text { Good thermal control is possible }\end{array}$ & $\begin{array}{l}\text { Contamination from probe (sonotrode) } \\
\text { tip erosion }\end{array}$ \\
& Sotial risk if cross-contamination \\
\hline Cup horn (indirect) & High rate of energy output & Availability in general and cost \\
& High level of thermal control possible & Smaller volumes can be processed \\
\hline
\end{tabular}


Figure 1. Illustration of different approaches to harmonisation of dispersion protocols. The protocol can either be prescriptive giving strict specifications (e.g. ENP concentrations, sonicator type, model and setting, mandatory pre-wetting step) or it can provide the overall framework but allow more flexibility and individual choices. At the same time, a protocol can be more general (with a specific range of applicability given) or it can be tailored to a specific ENP (or a group of ENPs). Harmonization and standardisation of dispersion protocols will always be a compromise between optimum dispersion for specific ENPs on one hand and compatibility between test systems and ENPs on the other hand. 


\section{Page 51 of 53 Journal of Toxicology and Environmental Health, Part B: Critidal Reviews}

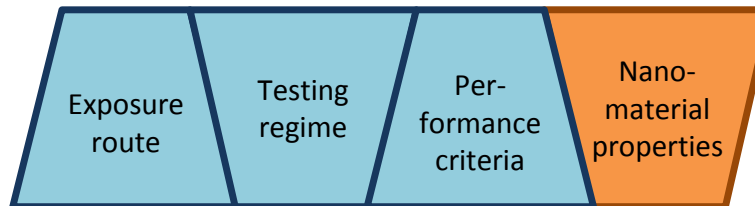

Collect information

Action \& documentation

Material and test-specific considerations

Observation /characterisation

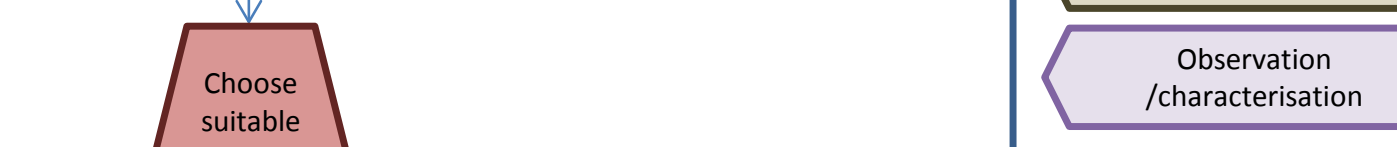

Use in bioassays
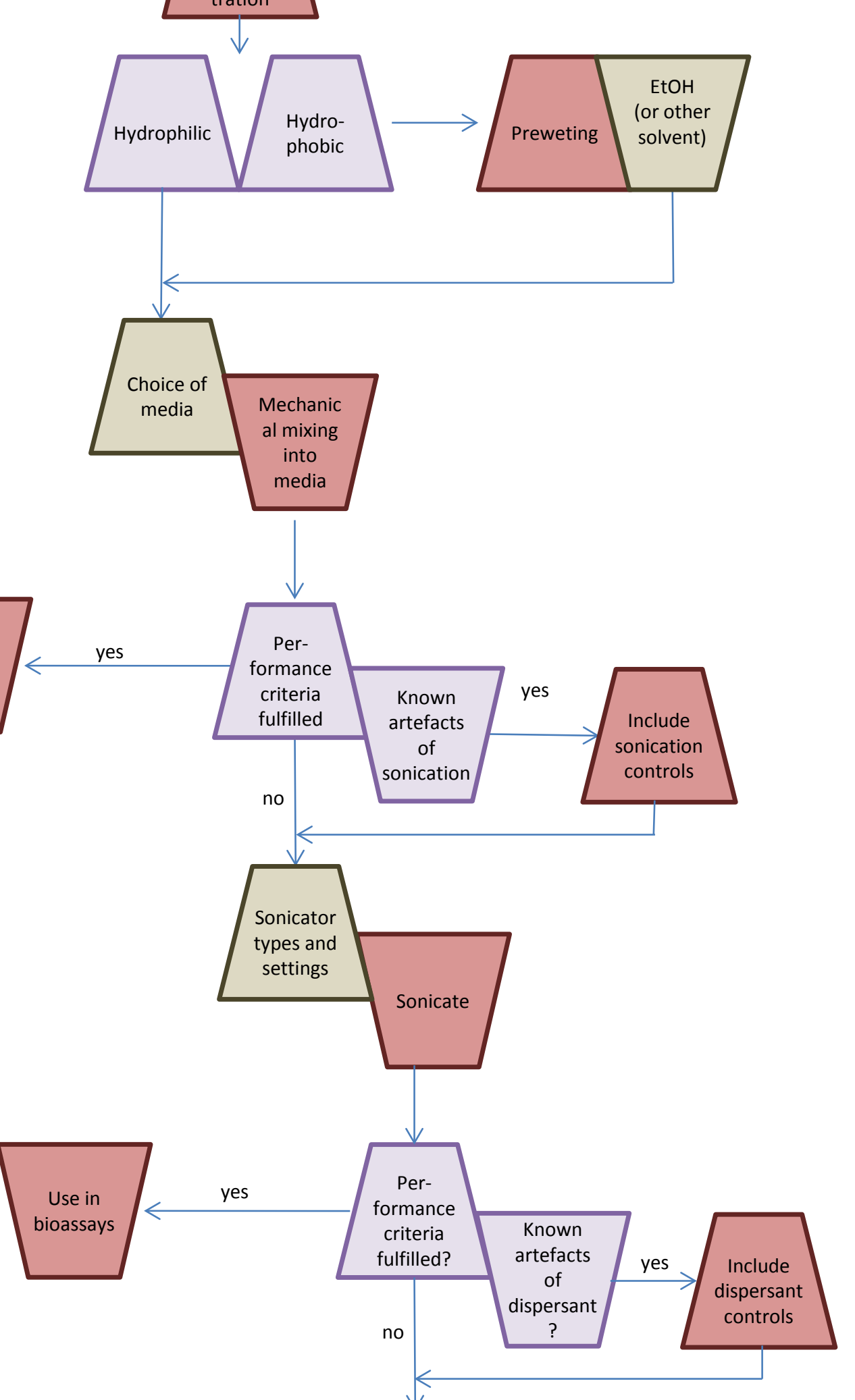

no

of
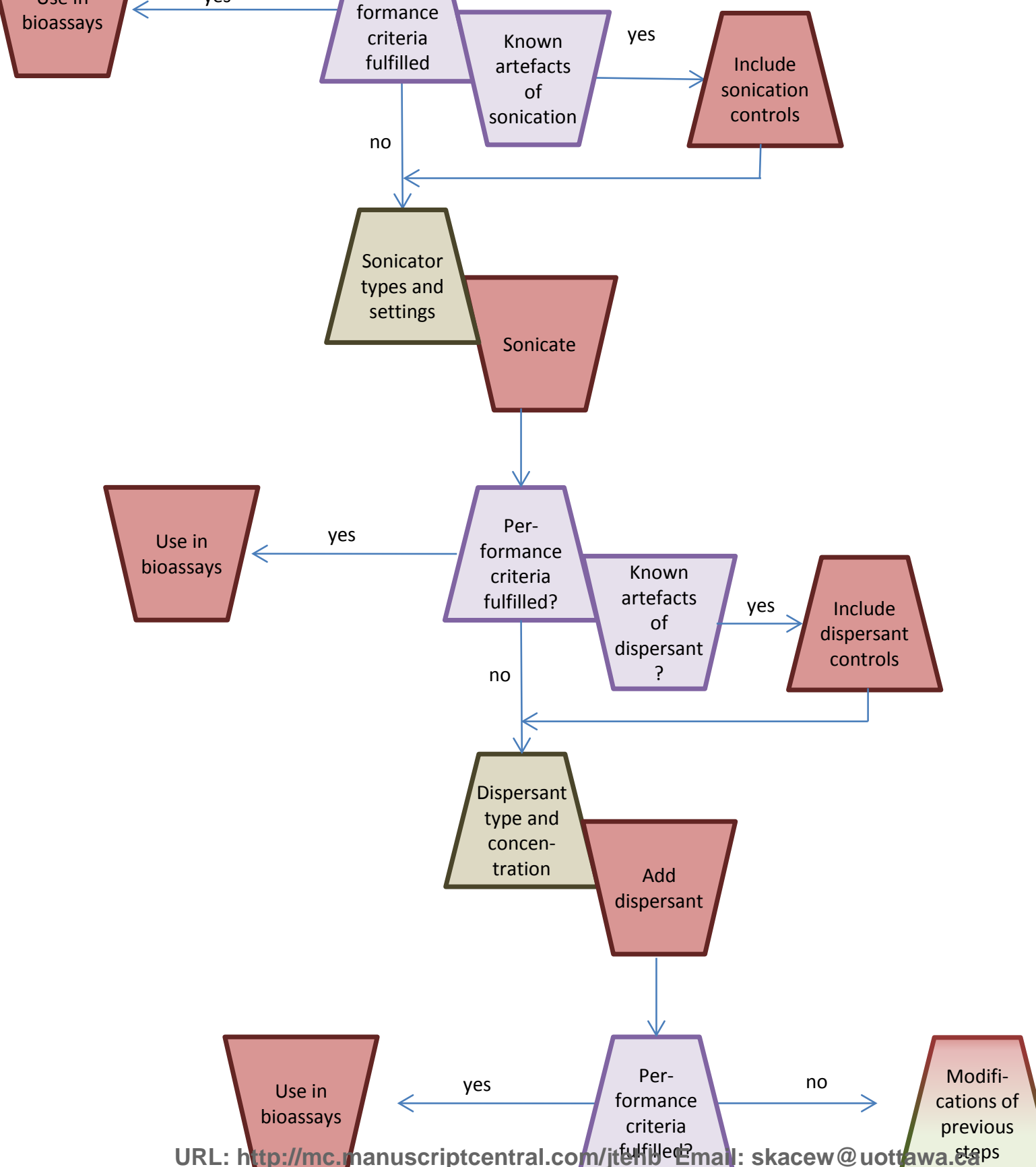

URL: htto://mc.hnanuscriptcentral.com/iteffilledemal!: skacew@uottawa.etęps 


\section{SUPPORTING INFORMATION}

Table S1. Examples of the influence of sonication on biological effects in ecotoxicity (and toxicity) testing

\begin{tabular}{|c|c|c|c|c|c|}
\hline $\begin{array}{l}\text { Nanoparticle } \\
\text { type }\end{array}$ & $\begin{array}{l}\text { Type of } \\
\text { sonication }\end{array}$ & Type of organism / cell & Influence of sonication & Other observations & Reference \\
\hline $\mathrm{CuO}$ & $\begin{array}{l}\text { Bath } \\
\text { (Intersonic, IS-2, } \\
300 \mathrm{~W}, 35 \mathrm{kHz} \text { ) }\end{array}$ & $\begin{array}{l}\text { Nitellopsis } \\
\text { obtusa } \quad \text { (macrophytic } \\
\text { algae) } \\
\text { Chlorella } \quad \text { (microphytic } \\
\text { algae) } \\
\text { Thamnocephalus } \\
\text { platyurus (shrimp) } \\
\text { Brachionus calyciflorus } \\
\text { (rotifer) }\end{array}$ & $\begin{array}{l}\text { No substantial differences in toxicity between } \\
\text { sonicated and non-sonicated dispersions. } \\
\text { However sonicated dispersion was more toxic } \\
\text { than non-sonicated dispersion in the case of } \\
N \text {. obtusa, and the opposite situation was } \\
\text { found for B. calyciflorus) }\end{array}$ & $\begin{array}{l}\text { Re-agglomeration was observed } \\
\text { immediately after sonication within } 15 \mathrm{~s} \text {, } \\
\text { and the particle size distributions of } \\
\text { nonsonicated and sonicated } 30-\mathrm{mg} / \mathrm{L} \\
\text { nCuO dispersions practically did not } \\
\text { differ after } 5 \text { min }\end{array}$ & [1] \\
\hline Ag & $\begin{array}{l}\text { Bath } \\
\text { (Branson } \\
\text { Ultrasonics, } 2510 \\
\text { Ultrarranic } \\
\text { cleaner, } 15 \mathrm{kHz} \text { for } \\
1.5 \mathrm{~h} \text { ) }\end{array}$ & P. promelas embryos & $\begin{array}{l}\text { A short sonication period }(5 \mathrm{~min}) \text { just prior to } \\
\text { testing resulted in a significant increase in } \\
\text { mortality compared to exposure to particles } \\
\text { that were just stirred. Similar amounts of } \\
\text { dissolved Ag were released from the Sigma } \\
\mathrm{Ag} \text { NPs tested regardless if solutions were } \\
\text { stirred or sonicated ( } \mathrm{p}>0.05) \text {, but with } \\
\text { concentrations increasing significantly with } \\
\text { increasing concentrations (all comparisons } \mathrm{p} \\
>0.05 \text { ) }\end{array}$ & $\begin{array}{l}\text { Sonication resulted in a decrease in the } \\
\text { formation of aggregates compared to } \\
\text { solutions that were only stirred, } \\
\text { regardless of NP size. }\end{array}$ & [2] \\
\hline TiO2 & $\begin{array}{l}\text { Probe sonication } \\
\text { (QSonica, } \\
\text { Sonicator } 4000 \text {, } \\
\text { Newton, CT) for } 5 \\
\text { minutes at } 20 \mathrm{kHz} \text {, } \\
20 \mathrm{~mm}, 0.5 \text { inch } \mathrm{Ti} \\
\text { horn) }\end{array}$ & H.azteca & $\begin{array}{l}\text { Sonication of } \mathrm{TiO}_{2} \text { NP stock solutions } \\
\text { increases toxicity compared to stirred } \\
\text { solutions. Also, in general, animals exposed } \\
\text { to sonicated } \mathrm{TiO}_{2} \text { showed significantly lower } \\
\text { dry weight than stirred groups. }\end{array}$ & - & [3] \\
\hline $\mathrm{CeO}_{2}$ & $\begin{array}{l}\text { Probe } \\
(1 \text { minute / } 70 \\
\text { watts) } \\
\text { Versus magnetic } \\
\text { stirring (vigorous, } \\
24 \mathrm{~h})\end{array}$ & $\begin{array}{l}\text { Daphnia magna } \\
\text { Ceriodaphnia dubia } \\
\text { Pseudokirchneriella } \\
\text { subcapitata }\end{array}$ & $\begin{array}{l}\text { For C. dubai: higher toxicity after exposure to } \\
\text { the probe sonicated dispersions compared to } \\
\text { stirred dispersions. } \\
\text { For P. subcapitata: although different } \\
\text { dispersal protocol leads to different } \\
\text { agglomerate size of } \mathrm{nCeO}_{2} \text {, the algae growth } \\
\text { inhibition were similar } \\
\text { For D. magna: no inhibition of the mobility } \\
\text { was recorded independent of media and } \\
\text { dispersion method }\end{array}$ & $\begin{array}{l}\text { The use of probe sonication as a dispersal } \\
\text { methods and the addition of HA ( } 2 \text { mg.L- } \\
1 \text {, TOC), were the optimal protocol to } \\
\text { produce small and consistent particles } \\
\text { sizes in dispersions, with a reasonable } \\
\text { stability over the exposure period. } \\
\text { Moreover this protocol appears to be the } \\
\text { most reproducible methods to disperse } \\
\text { the ceria nanopowder in the different } \\
\text { aqueous media. }\end{array}$ & [4] \\
\hline
\end{tabular}




\begin{tabular}{|c|c|c|c|c|c|}
\hline $\mathbf{C u}$ & $\begin{array}{lr}\text { Probe } \\
\text { (Sonifier } \\
\text { power supply with } \\
\text { converter } \quad \text { and } \\
\text { standard microtip } \\
\text { from } \quad \text { Branson } \\
\text { Sonic Power } \\
\text { Company (USA). } \\
\text { Approximate } \\
\text { output of } 14 \mathrm{~W} \text { in } \\
\text { a } 2 \mathrm{~mL} \text { dispersion) }\end{array}$ & $\begin{array}{l}\text { A549 cells (lung epithelial } \\
\text { cells) }\end{array}$ & $\begin{array}{l}\text { Significant difference }(\mathrm{p}>0.001) \text { in release } \\
\text { of } \mathrm{Cu} \text { from } \mathrm{Cu} \text { ENPs. All particles were } \\
\text { dissolved at sonicated conditions, whereas ca. } \\
65 \% \text { of the particles were dissolved in the } \\
\text { non-sonicated particle dispersion. Sonication } \\
\text { of the particle dispersion also influenced the } \\
\text { induced toxicity when compared to the non- } \\
\text { sonicated samples }(\mathrm{p}>0.001) \text {. } \\
\mathrm{NB!} \text { A higher extent of released Cu for } \\
\text { sonicated particle dispersions compared to } \\
\text { nonsonicated dispersions does not explain } \\
\text { well observed differences in toxicity. The } \\
\text { differences in size of particles and } \\
\text { agglomerates is a more plausible explanation }\end{array}$ & $\begin{array}{l}\text { Visual observations clearly revealed that } \\
\text { sonication rapidly changed the } \\
\text { appearance of the cell medium containing } \\
\text { visible large particle agglomerates to a } \\
\text { dark brownish appearance with no visible } \\
\text { large particle agglomerates }\end{array}$ & [5] \\
\hline
\end{tabular}

References

[1]: Manusadžianas, L., Caillet, C., Fachetti, L., Gylytè, B., Grigutytė, R., Jurkonienė, S., ... \& Férard, J. F. (2012). Toxicity of copper oxide nanoparticle suspensions to aquatic biota. Environmental Toxicology and Chemistry, 31(1), 108-114.

[2]: ( Laban, G., Nies, L. F., Turco, R. F., Bickham, J. W., \& Sepúlveda, M. S. (2010). The effects of silver nanoparticles on fathead minnow (Pimephales promelas) embryos. Ecotoxicology, 19(1), 185-195.

[3]: Malhi, G. S. (2012). The Chronic Toxicity of Titanium Dioxide Nanoparticles to the Freshwater Amphipod Hyalella azteca. MSc. Theseis, Wilfrid Laurier University. URL: http://scholars.wlu.ca/etd/839/ [accessed 31/03/2015]

[4]: Manier, N., Garaud, M., Delalain, P., Aguerre-Chariol, O., \& Pandard, P. (2011). Behaviour of ceria nanoparticles in standardized test media-influence on the results of ecotoxicological tests. In Journal of Physics: Conference Series (Vol. 304, No. 1, p. 012058). IOP Publishing.

[5]: Cronholm, P., Midander, K., Karlsson, H. L., Elihn, K., Wallinder, I. O., \& Möller, L. (2011). Effect of sonication and serum proteins on copper release from copper nanoparticles and the toxicity towards lung epithelial cells.Nanotoxicology, 5(2), 269-281. 